\title{
mGluR5 in Cortical Excitatory Neurons Exerts Both Cell-Autonomous and -Nonautonomous Influences on Cortical Somatosensory Circuit Formation
}

\author{
Carlos J. Ballester-Rosado, ${ }^{1,2}$ Michael J. Albright, ${ }^{1}$ Chia-Shan Wu, ${ }^{1}$ Chun-Chieh Liao, ${ }^{1,5}$ Jie Zhu, ${ }^{1}$ Jian Xu, ${ }^{4}$ Li-Jen Lee, ${ }^{5}$ \\ and Hui-Chen $\mathrm{Lu}^{1,2,3}$ \\ ${ }^{1}$ The Cain Foundation Laboratories, Department of Pediatrics, ${ }^{2}$ Program in Developmental Biology, and ${ }^{3}$ Department of Neuroscience, Baylor College of \\ Medicine, Houston, Texas 77030, ${ }^{4}$ Salk Institute, San Diego, California 92186, and ${ }^{5}$ National Taiwan University, Taipei, Taiwan 10617
}

\begin{abstract}
Glutamatergic neurotransmission plays important roles in sensory map formation. The absence of the group I metabotropic glutamate receptor 5 (mGluR5) leads to abnormal sensory map formation throughout the mouse somatosensory pathway. To examine the role of cortical mGluR5 expression on barrel map formation, we generated cortex-specific mGluR5 knock-out (K0) mice. Eliminating mGluR5 function solely in cortical excitatory neurons affects, not only the whisker-related organization of cortical neurons (barrels), but also the patterning of their presynaptic partners, the thalamocortical axons (TCAs). In contrast, subcortical whisker maps develop normally in cortical-mGluR5 KO mice. In the S1 cortex of cortical-mGluR5 K0, layer IV neurons are homogenously distributed and have no clear relationship to the location of TCA clusters. The altered dendritic morphology of cortical layer IV spiny stellate neurons in corticalmGluR5 KO mice argues for a cell-autonomous role of mGluR5 in dendritic patterning. Furthermore, morphometric analysis of single TCAs in both cortical- and global-mGluR5 K0 mice demonstrated that in these mice, the complexity of axonal arbors is reduced, while the area covered by TCA arbors is enlarged. Using voltage-clamp whole-cell recordings in acute thalamocortical brain slices, we found that KO of mGluR5 from cortical excitatory neurons reduced inhibitory but not excitatory inputs onto layer IV neurons. This suggests that mGluR5 signaling in cortical excitatory neurons nonautonomously modulates the functional development of GABAergic circuits. Together, our data provide strong evidence that mGluR5 signaling in cortical principal neurons exerts both cell-autonomous and -nonautonomous influences to modulate the formation of cortical sensory circuits.
\end{abstract}

\section{Introduction}

The group I metabotropic glutamate receptor 5 (mGluR5) is a G-protein-coupled receptor that primarily signals via $\mathrm{G} \alpha_{\mathrm{q} / 11}$ and modulates various kinases, ion channels, and intracellular calcium stores through DAG and IP3 signaling (for review, see Niswender and Conn, 2010). At many mature synapses, activation of mGluR5 can trigger endocannabinoid synthesis (Rouach and Nicoll, 2003; Kettunen et al., 2005; Kreitzer and Malenka, 2005; Safo and Regehr, 2005) and/or activate local dendritic translational machinery (for review, see Lüscher and Huber, 2010). mGluR5 has also been implicated in the pathology of several significant neurodevelopmental disorders, including Fragile X syndrome, autism, and epilepsyassociated malformations in cortical development (Catania et al.,

\footnotetext{
Received May 13, 2010; revised 0ct. 5, 2010; accepted 0ct. 7, 2010.

This work is supported by National Institutes of Health (NIH) Grants NS048884 (H.C.L.) and 5T32HD055200 (M.A.) and the National Alliance for Research on Schizophrenia and Depression (H.C.L.). We also thank the Baylor Intellectual and Developmental Disabilities Research Center core facility (NIH HD024064) for access to confocal microscopy and Deena Parghi for the help with Golgi staining. We thank Dr. Shen-Ju Chou, Dr. Patricia Gaspar, Dr. Melis Inan, and Dr. Odessa Yabut for their helpful comments on the manuscript, Dr. Klaus-Armin Nave for providing NEX-Cre mice, and Dr. Kevin Jones for EMX-Cre mice.

Correspondence should be addressed to Hui-Chen Lu, Department of Pediatrics, Baylor College of Medicine, 1250 Moursund Street, Jan and Dan Duncan Neurological Research Institute, Suite 1225, Houston, TX 77030. E-mail: hclu@bcm.edu.

DOI:10.1523/JNEUROSCI.2462-10.2010

Copyright $\odot 2010$ the authors $\quad 0270-6474 / 10 / 3016896-14 \$ 15.00 / 0$
}

2007; Lüscher and Huber, 2010; Niswender and Conn, 2010). Thus, mGluR5 activity exerts enormous influence on neuronal processes, and understanding the different ways in which mGluR5 contributes to normal neural development and the neuropathology of neurological disorders is an area of intense research.

In mice, mGluR5 is expressed throughout the trigeminal system (Blue et al., 1997; Muñoz et al., 1999; López-Bendito et al., 2002) and is required for sensory map formation (Wijetunge et al., 2008; She et al., 2009). The cortical whisker map in the primary somatosensory (S1) cortex consists of discrete clusters of thalamocortical afferents (TCAs), relaying sensory information from individual whiskers, encircled by distinctive rings of cortical layer IV neurons (barrels) (Woolsey and Van der Loos, 1970; Killackey and Leshin, 1975). Thalamocortical synapses are glutamatergic, and studies with various transgenic mice have demonstrated the critical role of glutamatergic transmission in cortical whisker map formation (Erzurumlu and Kind, 2001; Kind and Neumann, 2001). The simultaneous appearance of TCA patterns and barrels (Rebsam et al., 2002) suggests cross talk between TCAs and cortical neurons as barrels are forming. Defective TCA patterns in the mutant mice with cortex-specific removal of NMDAR subunit NR1 (Iwasato et al., 2000; Datwani et al., 2002) provides strong evidence for cortical influences on TCA patterning.

In developing S1 cortex, mGluR5 is mainly localized in the postsynaptic compartments of excitatory synapses (Takasaki et 
al., 2008; Wijetunge et al., 2008) and plays important roles in dendritic morphogenesis of cortical layer IV neurons and in several aspects of synaptic function/plasticity at thalamocortical synapses (She et al., 2009). The defective TCA pattern in global mGluR5 knock-out (KO) mice raises the possibility that mGluR5 in excitatory cortical neurons exerts a feedback influence onto TCAs to shape neural circuit formation. However, it is possible that the aberrant cortical map in global mGluR5 $\mathrm{KO}$ mice is a "carryover" phenotype from map deficits in upstream sensory stations. To identify the site of mGluR5 action during cortical sensory map development, we generated cortex-specific mGluR5 $\mathrm{KO}$ mice and examined the development of whisker maps throughout the trigeminal system in these mice. We found that removing mGluR5 from cortical excitatory neurons disrupted both barrels and TCA patterns, similar to the disruption observed in global mGluR5 KO mice. Furthermore, mGluR5 KO layer IV neurons received reduced inhibitory inputs. Thus, cortical mGluR5 exerts both cell-autonomous and -nonautonomous effects to orchestrate cortical circuit formation.

\section{Materials and Methods}

Animals. Animals were treated in compliance with the U.S. Department of Health and Human Services and Baylor College of Medicine guidelines. mGluR5 conventional $\mathrm{KO}$ mice in a C57BL/6J background (B6.129Grm $5^{\mathrm{tm} 1 \text { Rod }} / \mathrm{J}$, stock number: 003558 ) were obtained from Jackson Laboratories. They were bred in an mGluR5 $5^{+/-}$and $\mathrm{mGluR} 5^{-1-}$ mating strategy to produce mGluR5 ${ }^{+/-}$and mGluR5 ${ }^{-1-}$ mice. mGluR5 ${ }^{+/-}$littermates were used as controls. In our previous work (She et al., 2009), breeding pairs of mGluR $^{+/-}$mice were set up to acquire $\mathrm{mGluR} 5^{+/+}, \mathrm{mGluR}^{+/-}$, and mGluR $5^{-1-}$ pups from the same litter, and no differences were observed between mGluR5 ${ }^{+/+}$and mGluR5 ${ }^{+/-}$mice. Both male and female mice were used in all the experiments described.

mGluR5 floxed (mGluR5 ${ }^{\mathrm{f} / \mathrm{f}}$ ) mice in a mixed $129 \mathrm{SVJ}$ and C57BL/6 background were generated by flanking the mGluR5 gene with a pair of loxPs (Xu et al., 2009). NEX-Cre (NEX ${ }^{\mathrm{Cre} / \mathrm{Cre}}$ ) mice in a mixed 129 SVJ and $\mathrm{C} 57 \mathrm{BL} / 6$ background were generated by knocking in the Cre gene into the NEX locus (Goebbels et al., 2006). In these mice, Cre activity is restricted to the excitatory neurons located in the cortex and hippocampus as early as E12.5. EMX-Cre (EMX $\left.{ }^{\text {Cre/Cre }}\right)$ mice in a mixed 129 SVJ and C57BL/6 background were generated by knocking in an IRES-Cre cDNA fragment into the $3^{\prime}$ noncoding region of EMX gene (Gorski et al., 2002). In these mice, Cre activity is present in excitatory neurons and glia but not GABAergic neurons in the cortex from E10.5 onwards. NEXmGluR5 KO mice were bred in a mGluR $5^{\mathrm{f} / \mathrm{f}} ; \mathrm{NEX}^{\mathrm{Cre} /+}$ and mGluR5 ${ }^{\mathrm{f} / \mathrm{f}}$ mating strategy to produce mGluR $5^{\mathrm{f} / \mathrm{f}} ; \mathrm{NEX}^{\mathrm{Cre} /+}$ (NEX-mGluR5 KO) and mGluR5 ${ }^{\mathrm{f} / \mathrm{f}} ; \mathrm{NEX}^{+/+}$(NEX-control) mice. EMX-mGluR5 KO mice were bred in a mGluR $5^{\mathrm{f} / \mathrm{f}} ; \mathrm{EMX}^{\mathrm{Cre} /+}$ and $\mathrm{mGluR} 5^{\mathrm{f} / \mathrm{f}}$ mating strategy to produce mGluR5 $^{\mathrm{f} / \mathrm{f}} ; \mathrm{EMX}^{\mathrm{Cre} /+}$ (EMX-mGluR5 KO) and mGluR5 ${ }^{\mathrm{f} / \mathrm{f}}$; $\mathrm{EMX}^{+/+}$(EMX-control) mice. The mixed genetic background from multiple crosses may result in heterogeneous phenotypes. To minimize these effects, littermate controls were used for all the experiments and processed simultaneously with the KO samples. All experiments and data analysis were done blind to genotype information.

Genotyping. Tail lysates were prepared by immersing tail pieces in 50 $\mathrm{mm} \mathrm{NaOH}$, boiling for $30 \mathrm{~min}$, vortexing vigorously for $10 \mathrm{~s}$, and then neutralizing with $1 \mathrm{~m}$ Tris- $\mathrm{HCl}, \mathrm{pH}$ 8.0. Tail lysates were then vortexed for another $10 \mathrm{~s}$ and centrifuged at $16,100 \times g$ for $1 \mathrm{~min}$. The supernatants were used as DNA templates for PCRs.

For mGluR5, PCRs were conducted with a mixture of primers MGWT1, MG-WT2, MG-Neo1, and MG-Neo2. The PCR products of the first primer mix were $442 \mathrm{bp}$ for the wt mGluR5 allele and $280 \mathrm{bp}$ for the KO allele. The primer sequences were as follows: MG-WT1: $5^{\prime}-\mathrm{CAC}$ ATG CCA GGT GAC ATC AT-3'; MG-WT2: 5' -CCA TGC TGG TTG CAG AGT AA-3'; MG-Neo1: 5' -CTT GGG TGG AGA GGC TAT TC CC-3'; MG-Neo2: 5' -AGG TGA GAT GAC AGG AGA TC-3'.

For the mGluR5 floxed allele, PCRs were conducted with a mixture of primers MGF-1 and MGF-2. The PCR products were $200 \mathrm{bp}$ for the wt
mGluR5 allele and $250 \mathrm{bp}$ for the loxP-flanked allele. The primer sequences were as follows: MGF-1: $5^{\prime}$-AGA TGT CCC ACT TAC CTG ATG T-3'; MGF-2: 5' -AGT TCC GTG TCT TTA TTC TTA GC-3'.

For NEX-Cre, PCRs were conducted with a mixture of primers NEX-F, NEX-R, and NCRE-R. The PCR products were $770 \mathrm{bp}$ for the wt allele and $520 \mathrm{bp}$ for the NEX-Cre allele. The primer sequences were as follows: NEX-F: 5' -GAG TCC TGG AAT CAG TCT TTT TC-3'; NEX-R: 5'-AGA ATG TGG AGT AGG GTG AC-3'; NCRE-R: 5' -CCG CAT AAC CAG TGA AAC AG-3'.

For EMX-Cre, PCRs were conducted with primers CRE-F and CRE-R. The PCR product was $500 \mathrm{bp}$. The primer sequences were as follows: CRE-F: 5'-GAT CTC CGG TAT TGA AAC TCC AGC-3'; CRE-R: 5' GCT AAA CAT GCT TCA TCG TCG G-3'.

Western blot analysis. Somatosensory cortices were isolated from P7 mice and homogenized as described previously (Lu et al., 2001). Protein concentrations were determined using the Bradford assay (Bio-Rad), and $25 \mu \mathrm{g}$ of total protein was electrophoretically separated on $4-15 \%$ gradient SDS-PAGE gels and transferred onto nitrocellulose membranes (Criterion system from Bio-Rad). Membranes were probed with rabbit anti- $\beta$-actin (Sigma; 1:2000) and rabbit anti-mGluR5 antibodies (Millipore; 1:3000). mGluR5 and $\beta$-actin immunoreactivity was detected with a LI-COR IRDye 800-conjugated donkey anti-rabbit secondary antibody (LI-COR), and visualized with an Odyssey scanner (LI-COR). Densitometric quantification was performed using NIH ImageJ software, the expression levels of each protein of interest were normalized to that of $\beta$-actin, and data are presented for each littermate control and conditional knock-out mouse normalized to the mean value of the corresponding littermate control.

Tissue preparation. Mice were deeply anesthetized by an injection (3 $\mathrm{ml} / \mathrm{kg}$ ) of an anesthetic cocktail containing ketamine $37.6 \mathrm{mg} / \mathrm{ml}$, xylazine $1.92 \mathrm{mg} / \mathrm{ml}$, and acepromazine $0.38 \mathrm{mg} / \mathrm{ml}$. Following establishment of anesthesia, mice were transcardially perfused with ice-cold PBS, $\mathrm{pH} 7.4$, followed by freshly prepared fixative (4\% paraformaldehyde in PBS, PFA, $\mathrm{pH}$ 7.4). The brains were then postfixed with the same fixative overnight at $4^{\circ} \mathrm{C}$.

Histology. The cytochrome oxidase (CO) staining of brain sections was conducted as described previously (Lu et al., 2001). Briefly, a fixed brain or flattened cortices (age range from P3 to P27) were sectioned to 50 or $100 \mu \mathrm{m}$ thickness with a Leica VT-1000 vibrating microtome (Leica Microsystems) and placed in PBS. For CO staining, slices were placed in the CO reaction solution ( $5 \mathrm{mg}$ of diaminobenzidine, $5 \mathrm{mg}$ of cytochrome $\mathrm{C}$, and $0.4 \mathrm{~g}$ of sucrose in $10 \mathrm{ml}$ of PBS, $\mathrm{pH} 7.4$ ) for $12-36 \mathrm{~h}$ at $4^{\circ} \mathrm{C}$. After staining, slices were rinsed with PBS and coverslipped for imaging.

Multiple immunofluorescent staining. Fixed brains were sectioned into $100 \mu \mathrm{m}$ thick sections in coronal or tangential planes as described previously (Lu et al., 2001). Free-floating sections were used for all subsequent steps. Sections were washed with PBST (PBS with $0.01 \%$ Triton X-100) and permeabilized with $0.2 \%$ Triton X-100 in PBS at room temperature for $20 \mathrm{~min}$. Sections were then washed with PBST, blocked for $1 \mathrm{~h}$ with $3 \%$ normal goat serum in PBST at room temperature, and then incubated with a mixture of two primary antibodies from different species in PBST with $2 \mathrm{mg} / \mathrm{ml} \mathrm{BSA}$ and $1 \%$ normal goat serum at $4^{\circ} \mathrm{C}$ overnight. The next day, sections were washed with PBST, and incubated with the appropriate fluorescent secondary antibodies in PBST at room temperature for $2 \mathrm{~h}$. Following this incubation, sections were washed with PBST twice for 5 min each. After DAPI staining (Invitrogen; 1:10,000 in PBS for $10 \mathrm{~min}$ ) to identify nuclei, sections were washed three times for $10 \mathrm{~min}$ each and mounted onto Superfrost Plus slides (Fisher Scientific), coverslipped with PBS, and sealed with nail polish for confocal imaging. Primary antibodies (source and dilutions): rabbit anti-VGluT2 (vesicular glutamate transporter 2) polyclonal Ab (Synaptic System; 1:750), guinea pig anti-vGluT2 (Millipore Bioscience Research Reagents; 1:4000), rabbit anti-mGluR5 (Millipore; 1:1000), rabbit anti $\beta$-Gal (Millipore Bioscience Research Reagents; 1:1000), and mouse anti-NeuN (Millipore Bioscience Research Reagents; 1:1000). Secondary antibodies (and dilutions): goat anti-guinea pig IgG-Alexa 488 (Invitrogen; 1:500), goat anti-rabbit IgG-Alexa 488, 594 (Invitrogen; 1:500), goat antimouse IgG-Alexa 488, 594 (Invitrogen; 1:500), goat anti-mouse IgG- 


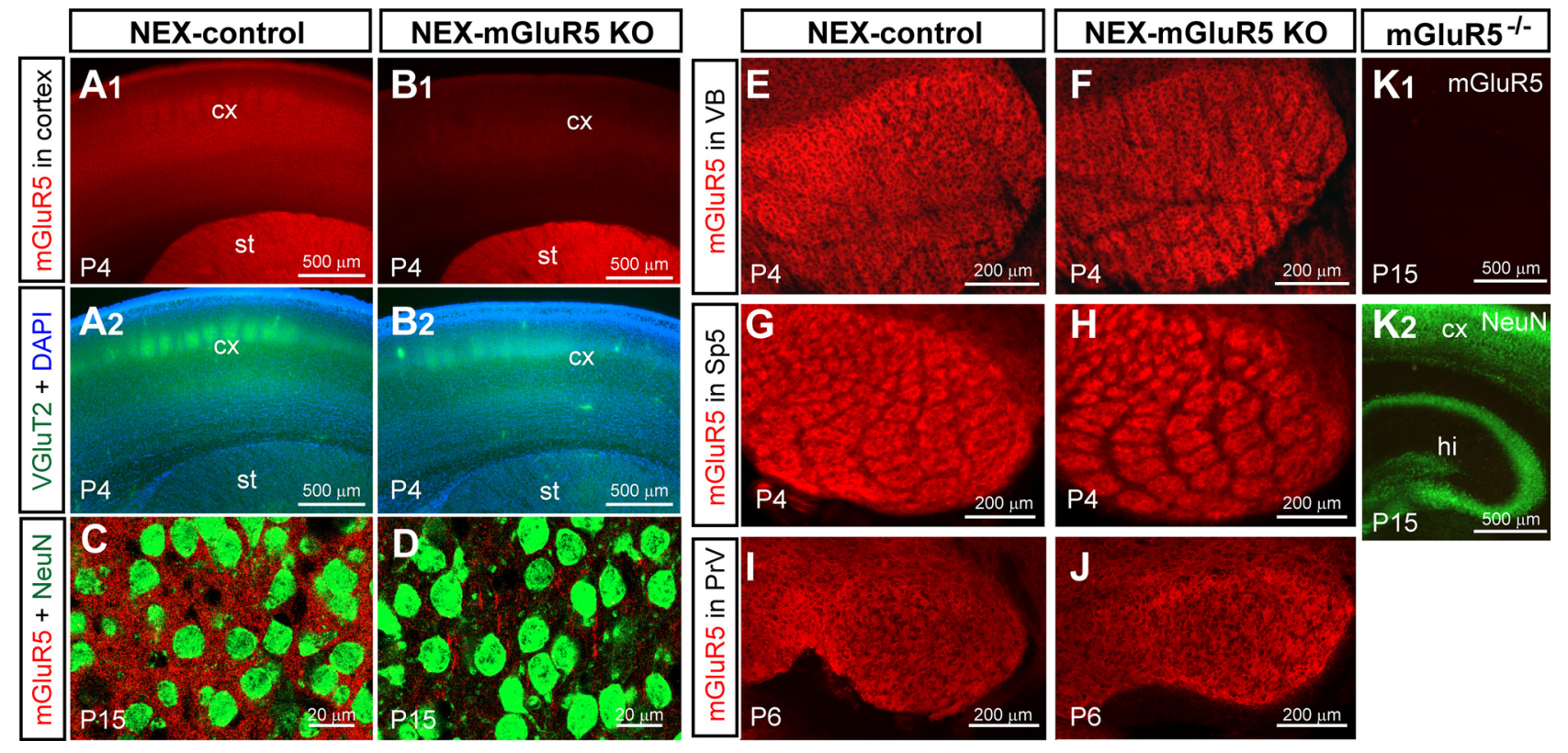

Figure 1. mGluR5 expression is reduced in a tissue-specific manner in conditional mGluR5 K0 mice. $A, B, m G l u R 5$ expression was substantially reduced in the cortex of P4 NEX-mGluR5 KO mice $\left(\boldsymbol{B}_{1}\right)$, while its expression in the striatum was similar to littermate controls (mGluR5 $\left.5^{\mathrm{f} / \mathrm{f}}\right)\left(\boldsymbol{A}_{\boldsymbol{1}}\right) . \boldsymbol{A}_{\mathbf{2}}$ and $\boldsymbol{B}_{2}$ show VGluT2 and DAPI staining in the same sections of $\boldsymbol{A}_{\boldsymbol{1}}$ and $\boldsymbol{B}_{1}$. $\boldsymbol{C}, \boldsymbol{D}$, High-magnification images in layer IV of P14 NEX-control $(\boldsymbol{C})$ and NEX-mGluR5 K0 S1 cortex (D). Prominent mGluR5-positive puncta outside NeuN-positive somata were seen in the control neuropil, while only residual mGluR5 immunoreactivity was observed in NEX-mGluR5 KO mice. $\boldsymbol{E}-\boldsymbol{J}$, Similar levels of mGluR5 expression in both NEX-control $(\boldsymbol{E}, \boldsymbol{G}, \boldsymbol{I})$ and NEX-mGluR5 K0 mice $(\boldsymbol{F}, \boldsymbol{H}, \boldsymbol{J})$ were found in the ventral basal $(\mathrm{VB})$ thalamus $(\boldsymbol{E}, \boldsymbol{F})$ and the brainstem nuclei Sp5 $(\boldsymbol{G}, \boldsymbol{H})$ and $\operatorname{PrV}(\boldsymbol{I}, \boldsymbol{J}) . \boldsymbol{K}$, No mGluR5 immunoreactivity was detected in mGluR5 ${ }^{-1-}$ mice $\left(\boldsymbol{K}_{\boldsymbol{1}}\right)$, while NeuN staining revealed distinctive structures $\left(\boldsymbol{K}_{\mathbf{2}}\right)$. The age of staining is indicated at the bottom left of each panel. cx, Cortex; PrV, principal sensory nucleus; Sp5, spinal trigeminal nucleus; st, striatum; VB, ventral basal thalamic nuclei.

Cy3 (Jackson ImmunoResearch Laboratories; 1:500), and goat antirabbit IgG-Cy5 (Jackson ImmunoResearch Laboratories; 1:500).

Imaging. Twenty-four-bit RGB digital bright-field images for histology were captured from an Olympus BX51 upright microscope under consistent light conditions using an Olympus DP70 CCD camera with Olympus DPC controller software with $2 \times / 0.08$ Plan Apo, $4 \times / 0.16$ UPlan Apo objectives (magnification/numerical aperture). Fluorescent images were obtained using a Zeiss AxioImager M1 system with $5 \times / 0.16$, $10 \times / 0.3$ Zeiss objectives, using AxioVision software. Confocal images were obtained using a Zeiss 510 system $100 \mathrm{M}$ Axiovert with $10 \times / 0.3$, $16 \times / 0.5,25 \times / 0.8$ (oil), $40 \times / 1.3$ (oil) objective lens. Alexa 488, Alexa 594 , Cy3, or Alexa 647 fluorophores were excited with lasers of appropriate excitation wavelength $(488 \mathrm{~nm}, 543 \mathrm{~nm}$, or $633 \mathrm{~nm})$ and scanned with emission filters selected to optimally separate fluorescence $(510 / 530$ bandpass filter for Alexa 488; 560/600 bandpass filter for Cy3 or Alexa 594; 660 long pass filter for Alexa 647). Each image was acquired with the laser intensity adjusted to prevent saturation. All images were processed as a whole in Adobe Photoshop CS2 for brightness/contrast, orientations, and background corrections to better illustrate the staining patterns. Regions of interest in digital images were copied and assembled into montages with Adobe Illustrator. Cytoarchitectonic areas and fiber tracts were annotated based on the Atlas of the Developing Mouse Brain (Jacobowitz and Abbott, 1998).

Analysis of the distribution of layer IV neurons relative to TCA clusters. One-hundred-micrometer-thick tangential brain slices after VGluT2 and NeuN double labeling were imaged using Zeiss AxioImager M1 system with $10 \times / 0.3$ Zeiss objectives. Fluorescent images were acquired at a resolution of $1388 \times 1040$ pixels, and each image encompassed an area of $61,000 \mu \mathrm{m}^{2}$ to include more than six TCA clusters representing C1, C2, and their adjacent whiskers. The VGluT2-positive area was defined as the barrel hollow. The $20-\mu \mathrm{m}$-thick belt encircling the hollow was defined as the barrel wall. The area between barrel walls was defined as the septum. Neurolucida software (MicroBrightField) was used to trace the boundaries of these three compartments and mark the cells within each domain separately. Next, the cell numbers in each domain and the area were measured by Neurolucida Explorer (MicroBrightField) to acquire the densities in each region. The neuron densities from each barrel hollow, wall, and septa in various genotypes were compared using nondirectional Student's $t$ test or Mann-Whitney rank-sum test (SigmaStat 3.5, Systat Software). The wall-to-hollow ratios of mutant mice compared to littermate controls were tested using Mann-Whitney rank-sum test. Data were presented as mean \pm SEM. All graphs were plotted using SigmaPlot 10 (Systat Software).

Golgi staining and analysis of dendritic morphology. Golgi stained neurons were obtained using the FD Rapid Golgi Stain kit (FD Neurotechnologies) based on Ramón-Moliner's Golgi-Cox technique (RamónMoliner, 1970). Brains were prepared according to the user manual, and 50 $\mu \mathrm{m}$ serial coronal sections were cut with a Microm HM550 cryostat (Mikron Instruments). Nissl counterstaining was performed right after Golgi staining and before dehydration, as described in the kit. Spiny stellate neurons were identified by the following criteria: (1) round-shape cell body, (2) a cell body diameter $<15 \mu \mathrm{m}$, and (3) the presence of dendritic spines. The Neurolucida (MicroBrightField) program was used to reconstruct spiny stellate neurons in three dimensions. Once the neuron was traced, NeuroExplorer (MicroBrightField) divided the traced neurons into a series of dendritic segments and measured the length and angle of each segment. A polar histogram was generated by collecting the dendritic segments into $10^{\circ}$-wide bins according to segment angle from 0 to $360^{\circ}$ and plotted with the total length of dendritic segments in a given bin. Dendritic asymmetry ratios were then calculated from the polar histograms by dividing the sum of the lengths of the greatest continuous $180^{\circ}$ (18 neighboring bins) by the total length of all dendritic segments. This produces a ratio from 0.5 (perfectly symmetric) to 1 (extremely asymmetric, occurring only if all the dendritic segments for a particular neuron all point in the same direction $\pm 5^{\circ}$ ). Neurons with a dendritic asymmetry value $>0.75$ were considered polarized.

Labeling of single TCAs. Mice of various genotypes were killed at P6-P7 for TCA labeling. After perfusion and fixation, the brains were extracted and postfixed in the fixative (4\% PFA). Brains were then cut at the appropriate angle with a Vibratome to preserve the thalamocortical projections (Lee et al., 2005). Two to three thick sections $(300 \mu \mathrm{m})$ per hemisphere were taken for thalamocortical afferent labeling. One small 

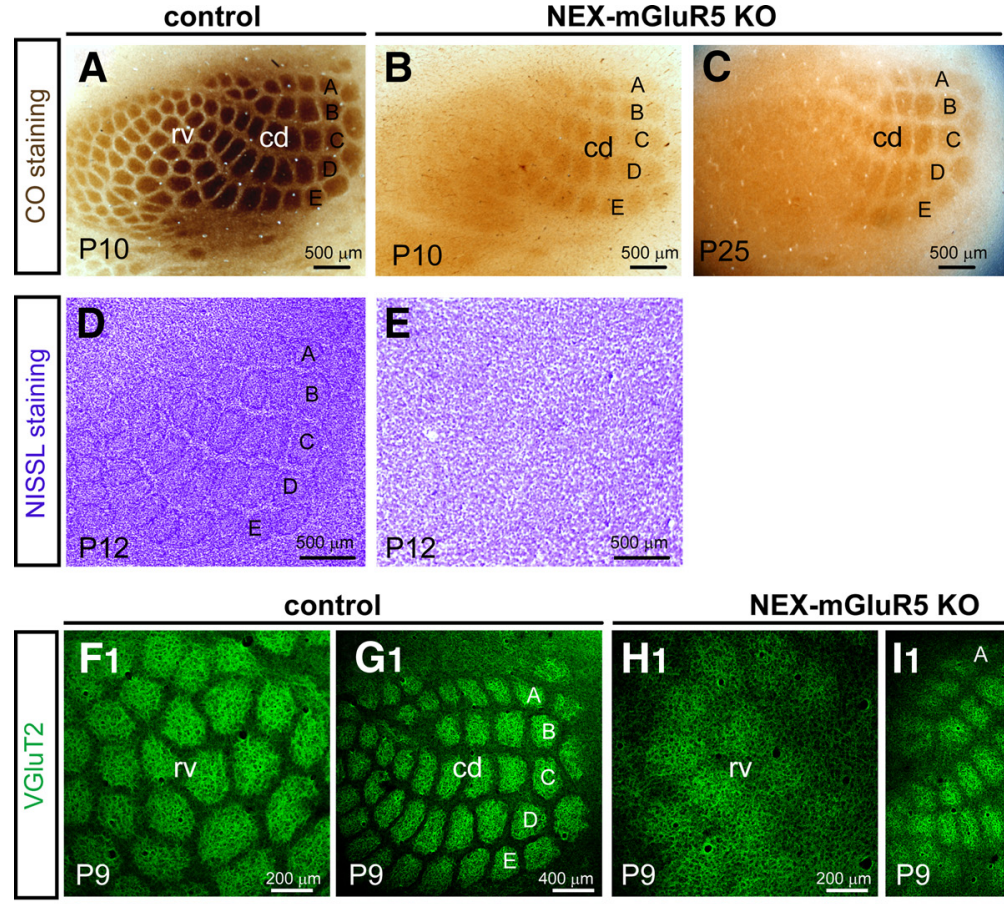

control
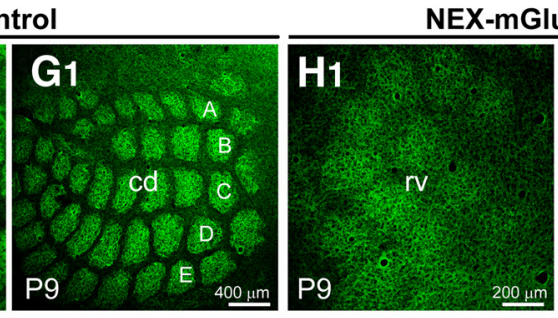

R5 KO
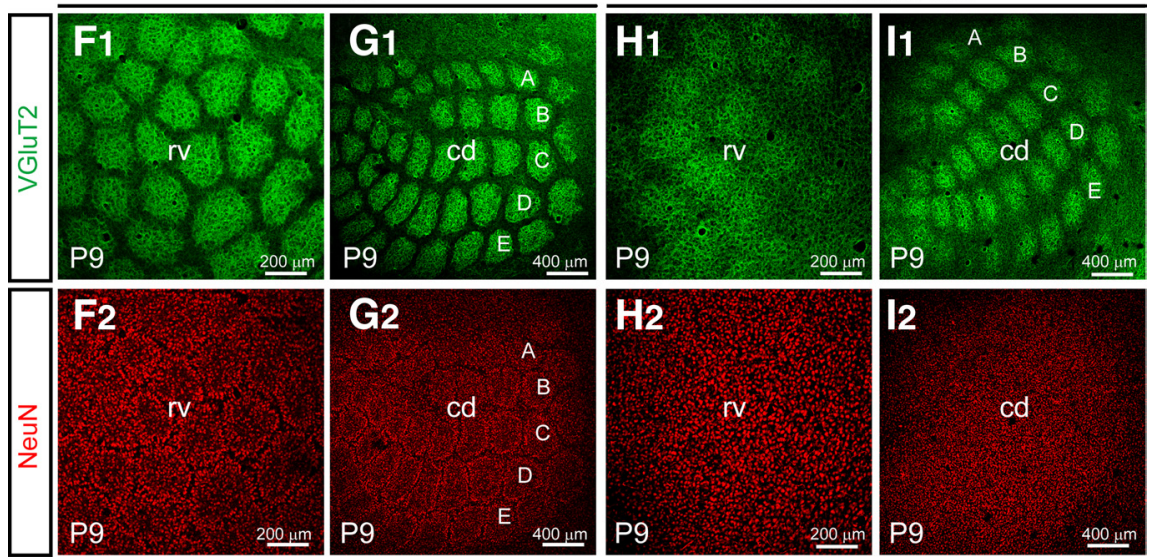

Figure 2. Abnormal whisker maps in NEX-mGluR5 KOS1 cortex. $A-D$, Representative images of C 0 -stained tangential sections through S1 cortical layer IV prepared from control $(\boldsymbol{A})$ and NEX-mGluR5 KO $(\boldsymbol{B}, \boldsymbol{C})$ mice. CO staining revealed whisker-related pattern in control mice $(\boldsymbol{A})$, while this staining showed whisker map deficits in the NEX-mGluR5 KO mice $(\boldsymbol{B}, \boldsymbol{C}) . \boldsymbol{D}, \boldsymbol{E}$, Nissl staining revealed normal barrel cytoarchitecture in control (D), but not in NEX-mGluR5 KO S1 cortex (E). $\boldsymbol{F}-\boldsymbol{I}$, VGluT2 and NeuN double labeling of tangential sections from control $(\boldsymbol{F}, \boldsymbol{G})$ and NEX-mGluR5 KOS1 cortex $(\boldsymbol{H}, \boldsymbol{I})$ were used to simultaneously visualize the distribution of TCA clusters and cortical neurons. Unlike the discrete whisker-related VGluT2-positive patches in control mice $\left(\boldsymbol{F}_{\boldsymbol{1}}, \boldsymbol{G}_{\boldsymbol{\eta}}\right)$, fuzzy VGluT2-staining patterns were found in NEX-mGluR5 K0 mice $\left(\boldsymbol{H}_{1}, \boldsymbol{I}_{\boldsymbol{1}}\right)$, particularly for the TCA clusters related to the rostroventral whiskers $\left(\boldsymbol{H}_{\boldsymbol{1}}\right)$. NeuN staining revealed ring-like organizations of cortical neurons in control mice $\left(\boldsymbol{F}_{2}, \boldsymbol{G}_{2}\right)$, while no clear segregation of cortical neurons was observed in NEX-mGluR5 K0 mice $\left(\boldsymbol{H}_{2}, \boldsymbol{I}_{2}\right)$. A-E indicate the corresponding whiskers; $c$, the representation of the caudodorsal whiskers; rv, the representation of the rostroventral whiskers.

crystal of carbocyanine dye (DiI) (Invitrogen) was picked and inserted into the ventroposteromedial nucleus of thalamus with a 30 gauge needle under a dissection microscope. Sections were then placed in the fixative and kept in the dark for 4-6 weeks at room temperature for dye diffusion. The arborization patterns of identifiable single DiI-labeled TCAs were examined, and $1-\mu \mathrm{m}$-interval image stacks were acquired with Zeiss confocal microscope. Single TCAs were identified and their patterns were reconstructed from the point they entered the layer V/VI boundary, and all the arbors found within layers I-V were reconstructed with the Neurolucida program (MicroBrightField) in three dimensions. The following morphometric features of axonal arbor topology were measured using Neurolucida Explorer (MicroBrightField): the number of segments per branch order, segment lengths per branch order, the highest branch order, the total number of segments and length (from the first bifurcation point; the second order), and the maximal lateral span covered by the TCA's projection. The total number of branches of single TCAs in cortical layers I-V from mGluR $5^{\mathrm{f} / \mathrm{f}}, \mathrm{mGluR} 5^{+/-}$, and NEX-mGluR5 ${ }^{+/-}$mice were $35.25 \pm 1.28, n=12,33 \pm 1.81, n=6$, and $33.86 \pm 1.95, n=7$, respectively. Because the overall pattern and quantitative features of TCAs from these three groups of mice were similar, their data were pooled together and constituted the control group.

In vitro electrophysiology and data analysis. Acute thalamocortical brain slices were prepared from P9-P15 (day of birth is P0) mouse pups as described previously (Lu et al., 2001). Slices were maintained and recorded at $32-34^{\circ} \mathrm{C}$ in artificial CSF (ACSF; compositions in mM: 124 $\mathrm{NaCl}, 5 \mathrm{KCl}, 1.25 \mathrm{NaH}_{2} \mathrm{PO}_{4}, 1.3 \mathrm{MgSO}_{4}, 2$ $\mathrm{CaCl}_{2}, 26 \mathrm{NaHCO}_{3}$, and 11 glucose) saturated with $95 \% \mathrm{O}_{2}$ and $5 \% \mathrm{CO}_{2}$. Voltage-clamped EPSCs were recorded from layer IV neurons in S1 cortex using a Multiclamp 700B amplifier (Molecular Devices). Data were collected (10 $\mathrm{kHz}$ sampling rate with $2 \mathrm{kHz}$ Bessel filter) using pClamp 10.2 (Molecular Devices) and analyzed with Clampfit. The majority of layer IV neurons are spiny stellate neurons. Thus, cells $\sim 10 \mu \mathrm{m}$ in diameter without an obvious primary dendrite were chosen for recording to avoid interneurons (usually small in size) and pyramidal neurons (which tend to have large cell bodies and apical dendrite). To evaluate and monitor the health of the cell, input and series resistances were continuously monitored and only data from cells in which these parameters remained stable throughout the recording were used for further analysis.

To record mEPSCs and mIPSCs, the cells were held at $-70 \mathrm{mV}$ and $1 \mu \mathrm{m}$ tetrodotoxin was included in the perfusate to block sodium-dependent action potentials. mEPSCs were recorded using a whole-cell recording solution (containing the following in mM: 117.5 cesium gluconate, $17.5 \mathrm{CsCl}, 8$ $\mathrm{NaCl}, 10$ HEPES, 0.2 EGTA, $4 \mathrm{Mg}$-ATP, 0.3 GTP, and 7 phosphocreatine, pH 7.2, $290-$ $300 \mathrm{mOsm}$ ) and isolated by washing in $10 \mu \mathrm{M}$ gabazine, a $\mathrm{GABA}_{\mathrm{A}}$ receptor blocker, and 50 $\mu \mathrm{M}$ APV, an NMDA receptor blocker. To record mIPSCs, neurons were patched with high-chloride whole-cell internal solution (containing the following in mM: 137 potassium chloride, $8 \mathrm{NaCl}, 10$ HEPES, 0.2 EGTA, $4 \mathrm{Mg}$-ATP, $0.3 \mathrm{GTP}$, and 7 phosphocreatine), and $10 \mathrm{~mm}$ kynurenic acid was included in the external Ringer's solution to block all glutamate receptors.

Current-clamped whole-cell recordings were conducted for layer IV neurons in S1 cortex using a Multiclamp 700B amplifier with a potassiumbased internal solution (containing the following in mM: 117.5 potassium gluconate, $17.5 \mathrm{KCl}, 8 \mathrm{NaCl}, 10 \mathrm{HEPES}, 0.2 \mathrm{EGTA}, 4 \mathrm{Mg}$-ATP, $0.3 \mathrm{GTP}$, and 7 phosphocreatine, $\mathrm{pH} 7.2,290-300 \mathrm{mOsm})$. We examined the resting membrane potential $\left(V_{\text {rest }}\right)$, input and series resistance $\left(R_{\text {in }}\right)$. The membrane time constant $\left(\tau_{\mathrm{m}}\right)$ was determined by fitting the change of membrane potential from the resting potential to -80 or $-90 \mathrm{mV}$ with a singleexponential function. A series of current injection steps (range: $-100 \mathrm{pA}$ to $+300 \mathrm{pA}$ with $10 \mathrm{pA}$ per step) were given to evoke action potentials (APs). Current pulse durations were $150 \mathrm{~ms}$ for AP property analysis and $600 \mathrm{~ms}$ for AP train analysis. Single-AP properties, including threshold, amplitude, the amplitude/time of the afterhyperpolarization (AHP), were measured from the first induced AP. The AP threshold was determined as the absolute membrane potential at the onset of the AP. The AP amplitude was measured from threshold to the peak of the spike. The amplitude of the AHP was measured from the threshold to the maximum AHP. For establishing the relationship of AP frequency and injected currents, the frequency of AP generated by the depolarizing current series was plotted. AP5 train data were analyzed in AP trains with 5-6 spikes. Rheobase was the minimal injected current that resulted in an AP. All summary data are presented as means \pm SEM. Student's $t$ test was used to determine statistical significance except where otherwise specified (SigmaStat 3.5). 

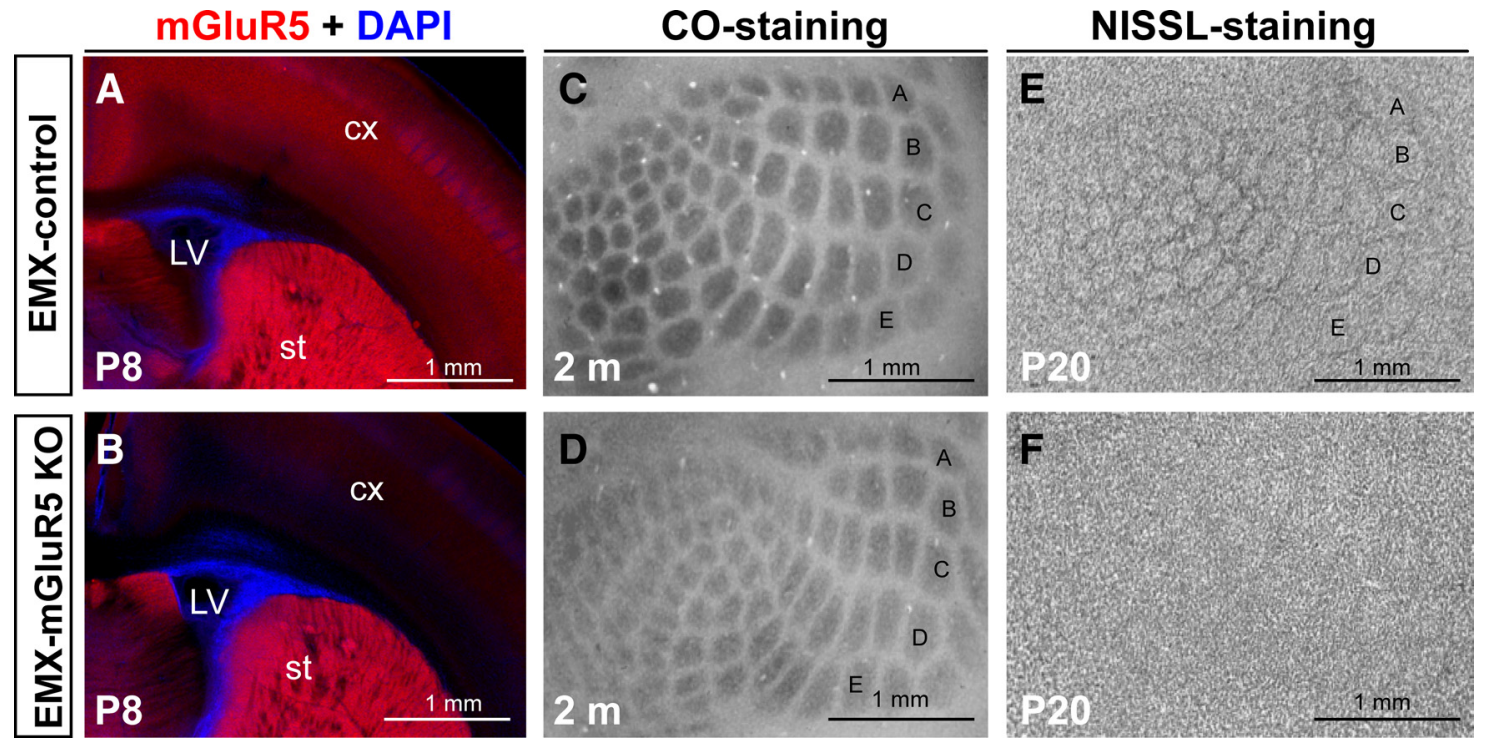

Figure 3. EMX-mGluR5 K0 mice have a cortex-specific reduction in mGluR5 expression and a defective cortical whisker map. $A, B$, mGluR5 expression was substantially reduced in the cortex of P8 EMX-mGluR5 K0 mice $(\boldsymbol{B})$, while its expression in subcortical areas, including the striatum, was similar to their littermate controls (mGluR5 ${ }^{\mathrm{f} / \boldsymbol{f}}$ ) mice $(\boldsymbol{A})$. $\boldsymbol{C}, \boldsymbol{D}$, Representative images of $C 0$-stained tangential sections through cortical layer IV prepared from EMX-control ( () and EMX-mGluR5 KO (D) S1 cortex. $\boldsymbol{E}, \boldsymbol{F}$, Nissl staining revealed classic barrel cytoarchitecture in control $(\boldsymbol{E})$ but not in EMX-mGluR5 KOS1 cortex $(\boldsymbol{F}) .2$ m, 2 months old; A-E indicate the corresponding whiskers; LV, lateral ventricle; st, striatum.

\section{Results}

Tissue-specific mGluR5 deletion in conditional knock-out mice

Cortex-specific mGluR 5 conditional KO mice were generated by crossing mGluR5 floxed (mGluR5 ${ }^{\mathrm{f} / \mathrm{f}}$ ) mice (Xu et al., 2009) with NEX-Cre mice (Gorski et al., 2002; Goebbels et al., 2006) (see Materials and Methods for details). In NEX-mGluR5 KO (NEXCre; $m$ GluR $5^{\mathrm{f} / \mathrm{f}}$ ) mice, mGluR5 gene in the cortical glutamatergic principal neurons is deleted. To confirm the cortex-specific deletion of mGluR5 expression, mGluR5 and VGluT2 (vesicular glutamate transporter 2) or NeuN double immunofluorescence staining was conducted with coronal brain sections prepared from P4-P15 control $(n=10)$ and NEX-mGluR5 KO $(n=9)$ mice (Fig. 1). In NEX-mGluR5 KO mice (Fig. $1 B$ ), mGluR5 expression was substantially and specifically reduced in the cortex compared to their wild-type littermates (Fig. 1A). mGluR5 expression in the subcortical areas, including the striatum (Fig. $1 A, B$ ), the thalamus (Fig. $1 E, F$ ), and the brainstem trigeminal complex (BSTC) (Fig. 1G-J), was similar between control and NEX-mGluR5 KO mice. No mGluR5 immunoreactivity was detected in global mGluR5 $\mathrm{KO}$ (mGluR5 ${ }^{-1-}$ ) mice, confirming the specificity of the mGluR5 antibody (Fig. $1 K)(n=3)$. Prominent mGluR5-positive puncta outside NeuN-positive somata were seen in the control neuropil (Fig. 1C), while only minimal residual mGluR5 immunoreactivity was observed in NEX-mGluR5 KO mice (Fig. 1D). These results demonstrate that mGluR5 expression in our NEX-mGluR5 KO mice was reduced in a cortexspecific manner.

Both TCAs and layer IV neurons fail to form whisker-related patterns in cortex-mGluR5 KO mice

In S1 cortical layer IV, TCAs carrying sensory information from the same whiskers are clustered into whisker-related bundles (barrel hollow) (Erzurumlu and Kind, 2001; Inan and Crair, 2007; Petersen, 2007) (for review, see Fox, 2008). Most layer IV neurons have their cell bodies to the side of the TCA clusters forming barrel walls, and send their dendrites toward the barrel hollow. Here, they form synapses with clusters of TCAs relaying

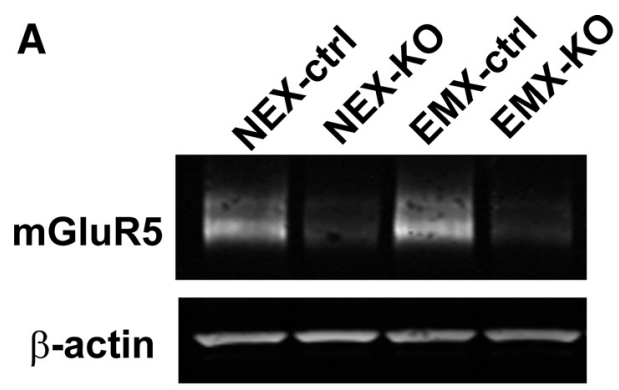

B

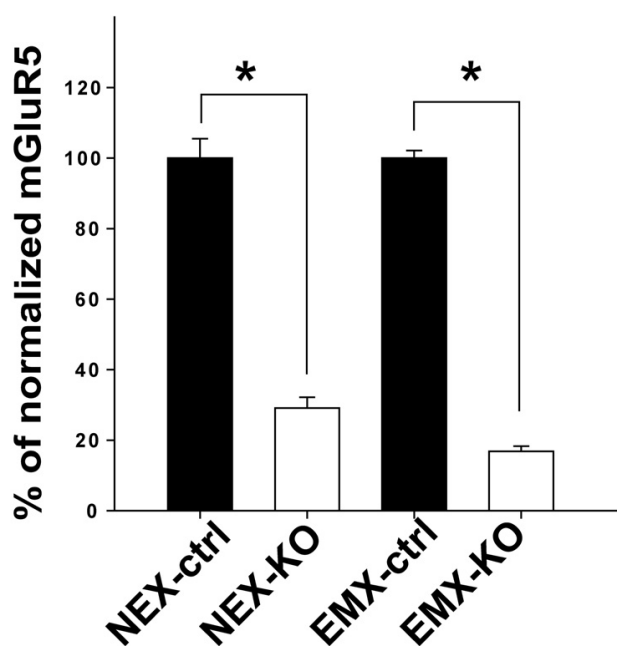

Figure 4. Quantitative comparison of mGluR5 expression in $\mathrm{S1}$ cortex of the cortex-specific knock-outs using Western blotting. $A$, Examples of the Western blots used to quantify the abundance of mGluR5 and $\beta$-actin in P7 S1 cortex from NEX- and EMX-mGluR5 K0 mice and their littermate controls. $\boldsymbol{B}$, Summary of the normalized ratios of $\mathrm{mGluR5} / \beta$-actin.

inputs from individual whiskers. To examine the formation of whisker-related patterns in NEX-mGluR5 KO S1 cortex, histochemistry with $\mathrm{CO}$ and Nissl staining (Fig. $2 A-E$ ) as well as immunostaining with thalamocortical and neuronal markers were 
conducted (Fig. $2 \mathrm{~F}-I$ ). In contrast to the discrete $\mathrm{CO}$ pattern observed in control mice (Fig. $2 A)(n>10)$, the boundaries of $\mathrm{CO}$-stained patches corresponding to the small rostroventral whiskers were very indistinct in NEX-mGluR5 KO mice (Fig. $2 B, C)(n>10)$.

Nissl staining revealed discrete barrel rings of layer IV neurons in control (Fig. $2 D)(n>10)$ mice. However, no clear cytoarchitectural differentiation of layer IV neurons into barrels was detected in NEX-mGluR5 KO mice (Fig. 2E). The NEX-Cre line is a knock-in for Cre expression in the NEX locus, and thus, in NEX-mGluR5 KO mice, one copy of the NEX gene is missing. No phenotype in NEX-null mutant mice was reported (Goebbels et al., 2006). Similarly, we did not observe a whisker map deficit in any of the following mice: $\mathrm{mGluR}^{\mathrm{f} /+} ; \mathrm{NEX}{ }^{\mathrm{Cre} / \mathrm{Cre}}$, mGluR5 ${ }^{\mathrm{f} /+} ; \mathrm{NEX}^{\mathrm{Cre} /+}, \mathrm{NEX}^{\mathrm{Cre} / \mathrm{Cre}}$, or $\mathrm{NEX}^{\mathrm{Cre} /+}$ (data not shown). To examine simultaneously the distribution of TCAs and cortical neurons, double labeling with VGluT2, a TCA marker (Fujiyama et al., 2001; Hur and Zaborszky, 2005; Nahmani and Erisir, 2005), and NeuN, a neuronal marker, was conducted with tangential sections (Fig. $2 F-I$ ) prepared from P7-P9 NEX-mGluR5 KO mice $(n=9)$ and their littermate controls $(n=9)$. In control S1 cortex, each whisker-related VGluT2-positive patch was matched with one patch of NeuNpositive neurons, with the majority of neurons lining up at the boundary (Fig. $2 F, G)$. Diffuse VGluT2-positive patches were observed in NEX-mGluR5 KO S1 cortex (Fig. $2 \mathrm{H}_{1}, I_{1}$ ), particularly for the TCA clusters related to the rostroventral whiskers (Fig. $2 \mathrm{H}_{1}$ ). Almost no (if any) whisker-related organization in NEXmGluR5 KO S1 cortex was revealed by NeuN staining (Fig. $2 \mathrm{H}_{2}, \mathrm{I}_{2}$ ). The defective whisker map observed in NEXmGluR5 KO S1 cortex is very similar to what we have observed previously in global mGluR5 KO mice (She et al., 2009). These data suggest that the mGluR5 in cortical glutamatergic neurons plays a central role in coordinating the development of both the presynaptic and postsynaptic components of thalamocortical connections.

A similar barrel map phenotype was found in EMX-mGluR5 KO S1 cortex (Fig. 3), an independent line of cortex-specific mGluR5 KO mice generated with the EMX-IRES-Cre line (Gorski et al., 2002). In EMX-mGluR5 KO (EMX-Cre;mGluR5 ${ }^{\mathrm{f} / \mathrm{f}}$ ) mice, the mGluR5 gene has been deleted from both cortical glia and excitatory neurons. mGluR5 immunostaining confirmed the cortex-specific removal of mGluR5 in P8 EMX-mGluR5 KO mice (Fig. $3 A, B)(n=3$ for each genotype). To examine the cortical whisker map in these mice, histochemistry with $\mathrm{CO}$ and Nissl staining were conducted in tangential sections through cortical layer IV of S1 cortex (Fig. 3C-F). In contrast to the discrete
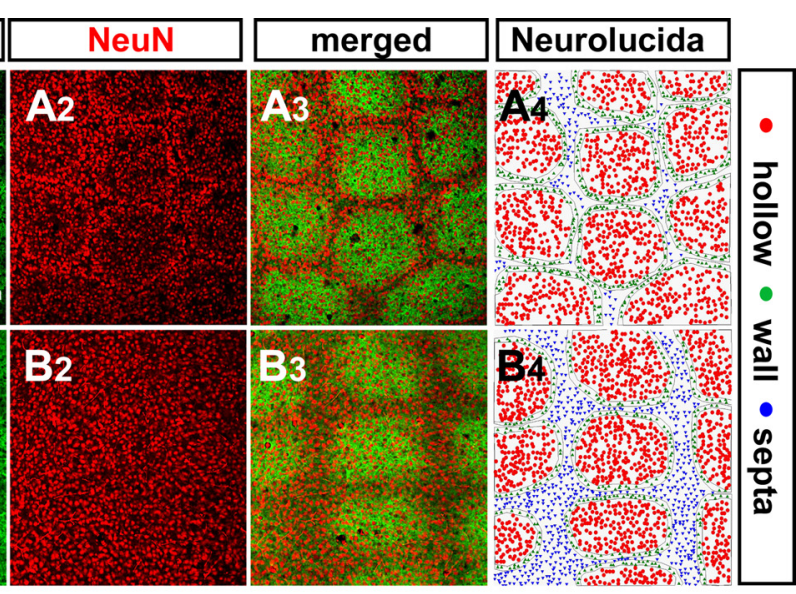

Figure 5. Layer IV neurons in NEX-mGluR5 K0 mice are evenly distributed within the barrel field. $\boldsymbol{A} \mathbf{1}-\boldsymbol{A} \mathbf{3}, \mathbf{B 1}-\mathbf{B} 3$, Representative immunostaining images show the distribution of TCAs and cortical neurons in tangential slices prepared as the septum. NeuN-positive cells $(\boldsymbol{A} \mathbf{2}, \mathbf{B} \mathbf{2})$ within the three domains were marked and counted using the

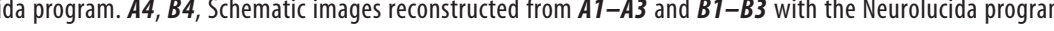
showing neuron density within these three compartments for both genotypes. In NEX-control mice, the density of layer IV cortical neurons was highest in barrel walls [neuron densities in \# of neurons $/(100 \mu \mathrm{m})^{2}$ : barrel hollow, $20.0 \pm 2.8$; barrel wall, $30.0 \pm 2.5$; barrel septa, $10.6 \pm 1.5 ; n=3 ; p=0.002$ between wall and hollow; $p<0.001$ between wall and septa;

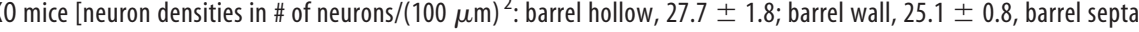
列 $n=3 ; p=0.228$ between wall and hollow; $p=0.152$ between wall and septa; $p=0.106$ between hollow 作 and EMX-mGluR5 K0 mice (EMX-control, $1.74 \pm 0.17, n=5$; EMX-mGluR5 K0, $0.96 \pm 0.06, n=4 ; p=0.016$ Mann-Whitney rank-sum test) compared to their littermate controls. Asterisks were used to indicate significant differences between the control group $\left({ }^{* *} p<0.01,{ }^{* * *} p<0.001\right)$.

CO pattern observed in littermate controls (Fig. $3 C)(n=8)$, fuzzy CO-stained patches corresponding to the small whiskers were observed in EMX-mGluR5 KO mice (Fig. $3 D)(n=11)$. Nissl staining revealed classic barrel rings formed by layer IV neurons in control S1 cortex (Fig. $3 E)(n=9)$. However, similarly to the NEX-mGluR5 KO mice, no clear cytoarchitectonic organization of layer IV neurons was observed in EMX-mGluR5 KO S1 cortex (Fig. $3 F)(n=13)$.

To quantify the level of mGluR5 expression in cortex-specific mGluR5 KO mice, Western blot analysis was conducted with P7 S1 cortex of NEX- and EMX-mGluR5 KO mice and their littermate controls ( $n=3$ for each genotypes) (Fig. 4). In NEXmGluR5 KO S1 cortex, mGluR5 expression level was $29 \pm 3 \%$ of their littermate controls (100 $\pm 6 \%$ ) (Fig. $4 B$ ). In EMX-mGluR5 KO S 1 cortex, mGluR 5 expression was $17 \pm 1 \%$ of the level of the littermate controls $(100 \pm 2 \%)$ (Fig. $4 B$ ). Thus, mGluR5 was 

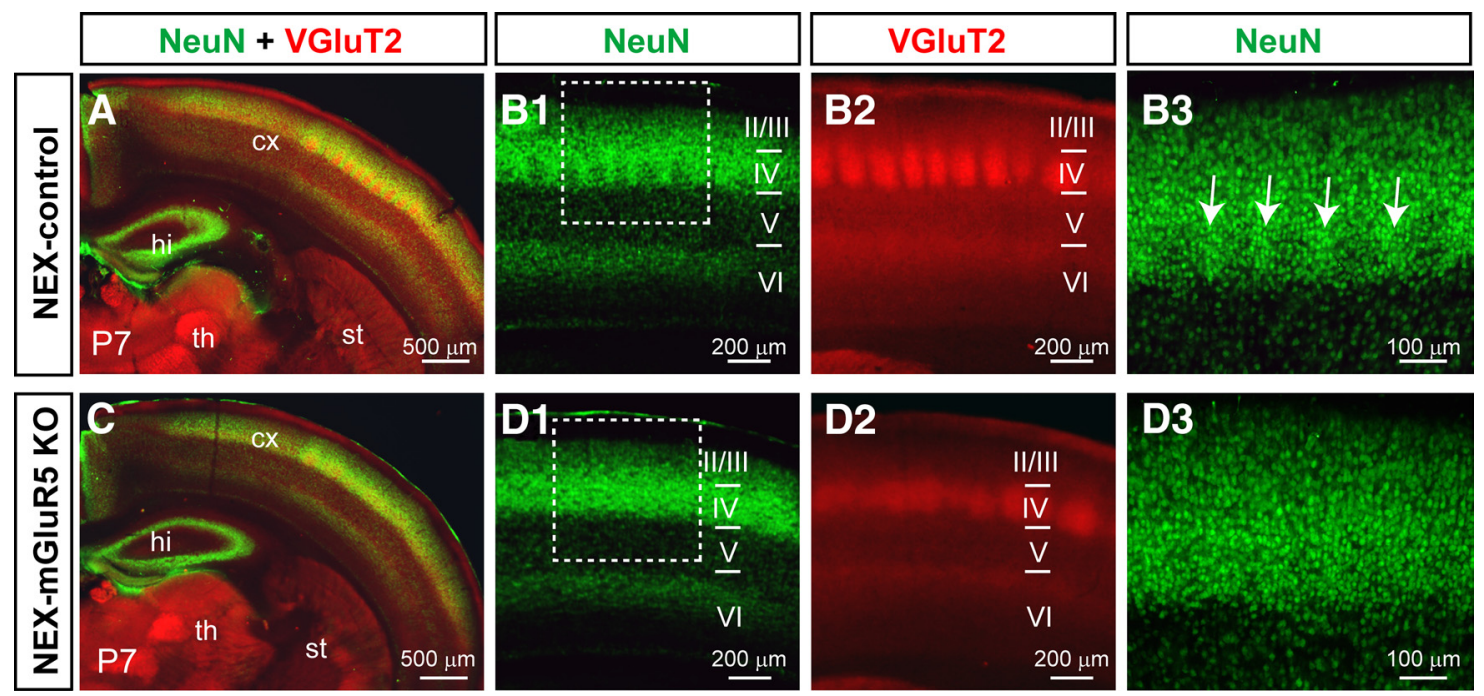

Figure 6. Barrel walls are absent in NEX-mGluR5 KO mice. NeuN (green) and VGluT2 (red) double labeling of coronal sections prepared from P7 NEX-control (A, B) and NEX-mGluR5 K0 mice (C, D). $\boldsymbol{B}, \boldsymbol{D}$, Enlarged views from $\boldsymbol{A}$ and $\boldsymbol{C}$. Similar cortical layering patterns between NEX-control (B1) and NEX-mGluR5 KO (D1) mice were revealed by NeuN labeling. VGluT2 immunoreactivity was enriched in cortical layers IV and VI of both genotypes (B2, D2). The distinctive barrel walls within cortical layer IV of control mice (arrows in B3) were absent in NEX-mGluR5 K0 mice (D3). Panel $\mathbf{3}$ images are the enlarged views from $\boldsymbol{B}_{1}$ and $\boldsymbol{D}_{1}$ (dashed boxes). II-VI, Cortical layers; cx, cortex; hi, hippocampus; st, striatum; th, thalamus.

substantially reduced in both NEX- and EMX-mGluR5 KO S1 cortex.

\section{Cortical mGluR5 signaling is required for barrel cytoarchitecture formation}

To quantitatively compare barrel cytoarchitectures among animals, we measured the densities of layer IV neurons within barrel hollows, barrel walls, and septa for P8-P9 control $(n=9)$ and NEX- $(n=3)$, and EMX- $(n=5)$ mGluR5 KO mice. To unambiguously identify the location of different barrel compartments and neurons, the analysis was conducted with VGluT2-NeuN double-stained cortical layer IV tangential slices (Fig. $5 A, B$ ). In NEX-control mice, the densities of layer IV cortical neurons were highest in the barrel walls, lower in the barrel hollows, and very low in the septa area, as expected (Fig. $5 C)(p=0.002$ between wall and hollow; $p<0.001$ between wall and septa; $p<0.001$ between hollow and septa). This striking differential distribution of cortical layer IV neurons was absent in NEX-mGluR5 KO mice (Fig. $5 C)(p=0.228$ between wall and hollow; $p=$ 0.152 between wall and septa; $p=0.106$ between hollow and septa). The ratios of wall-to-barrel hollow neuron densities were also significantly lower in both NEX- $(p=0.04)$ and EMX- $(p=0.016)$ mGluR5 KO mice compared to their littermate controls (Fig. 5D). These quantitative measures confirmed our earlier qualitative observations.

To further examine the formation of cortical layers and the distribution of TCA arbors, coronal sections cutting through the barrel field from P7 NEX-mGluR5 KO mice $(n=2)$ and their littermate controls $(n=2)$ were stained with VGluT2 and NeuN antibodies (Fig. 6). NeuN signals revealed barrel walls in layer IV of control S1 cortex but not in NEX-mGluR5 KO S1 cortex (Fig. $\left.6 B_{1}, B_{3}, D_{1}, D_{3}\right)$. In NEX-mGluR5 $\mathrm{KO}$ mice, six distinctive cortical layers of normal thickness were revealed by NeuN staining. The enriched VGluT2 immunoreactivity in cortical layers IV and VI of S1 cortex from both genotypes indicates that TCA target recognition occurred normally in NEX-mGluR5 KO mice (Fig. $\left.6 B_{2}, D_{2}\right)$. However, the distinct whisker-related VGluT2-positive patches seen in the layer IV of control S1 cortex (Fig. $6 B_{2}$ ) were ambiguous in NEX-mGluR5 KO S1 cortex (Fig. $6 D_{2}$ ). These re- sults suggest that mGluR5 in cortical neurons is required neither for proper cortical layer lamination nor for TCA layer-specific arborizations.

mGluR5 in cortical glutamatergic neurons plays a role in dendritic morphogenesis

The absence of barrel cytoarchitecture in both NEX- and EMXmGluR5 KO mice in a mixed 129/C57 genetic background indicates a requirement for mGluR5 signaling in cortical excitatory neurons in orchestrating the lateral placement of layer IV neurons as they form whisker-related patterns [for variations of barrel map deficits of mGluR5 KO mice in different genetic backgrounds, see Hannan et al. (2001)]. The majority of layer IV glutamatergic neurons are spiny stellate neurons that project their dendrites toward the barrel hollow (Woolsey et al., 1975; Steffen and Van der Loos, 1980; Lübke et al., 2000). The reduced dendritic polarity of layer IV spiny stellate neurons in many "barrelless" mutant mice (e.g., mGluR5, NR1, and NR2B KO mice) (Iwasato et al., 2000; Datwani et al., 2002; Espinosa et al., 2009; She et al., 2009) suggests a link between asymmetric dendritic morphogenesis and barrel formation.

To evaluate the influence of glutamatergic-mGluR5 on dendritic patterning, Golgi staining was conducted with P35 NEXmGluR5 KO mice $(n=5)$ and their littermate controls $(n=5)$ to examine dendritic morphogenesis of layer IV neurons (Fig. 7). Layer IV spiny stellate neurons in the S1 cortex were reconstructed in three dimensions and analyzed with Neurolucida. In NEX-control mice, $68 \%$ reconstructed neurons (23 of 34 ) showed a polarized distribution of their dendrites (defined in Materials and Methods) (Fig. $7 A, B, D, E$ ). In contrast, only $26 \%$ of NEX-mGluR5 KO neurons ( 8 of 31) had an orientation bias (Fig. 7C-E). The dendritic asymmetry of NEX-mGluR5 KO neurons was significantly reduced $(p<0.001)$ (Fig. $7 E)$. NEXmGluR5 KO neurons had more dendritic segments ( $p=0.002$, Mann-Whitney $U$ test) (Fig. $7 F$ ), and the total dendritic length was also much longer than control neurons $(p<0.001)$ (Fig. 7G). In NEX-mGluR5 KO neurons, the number of segments for the first to fourth branch orders was significantly larger than in control neurons (Fig. $7 \mathrm{H}$ ), while no substantial difference was observed for the aver- 
aged segment length per branch order (Fig. 7I). The dendritic span (the longest distance of the dendritic tips) was significantly larger in NEX-mGluR5 KO neurons (NEXcontrol, $137.26 \pm 12.10 \mu \mathrm{m}, 19$ neurons from 3 animals; NEX-mGluR5 KO neurons, $173.87 \pm 5.85 \mu \mathrm{m}, n=27$ neurons from 4 animals; $p=0.005$ ). The abnormalities in dendritic morphogenesis observed in NEX-mGluR5 KO mice are similar to our previous finding with the global mGluR5 KO mice (She et al., 2009). Thus, our data suggest that mGluR5 KO layer IV neurons failed to detect the position of rudimentary TCA clusters. Together, our results show that mGluR5 in cortical glutamatergic neurons modulates cytoarchitectonic differentiation and dendritic morphogenesis of layer IV neurons in a cell-autonomous manner and in guiding TCA arborizations in nonautonomous manner.

The complexity of the TCA arborization pattern is reduced in both global and cortex-mGluR5 KO mice

To uncover the anatomical substrates of cortical mGluR5 signaling on TCAs, we conducted a detailed morphometric analysis of single TCAs from the global and NEX-mGluR5 KO mice as well as their littermate controls. Similar arborization patterns were observed in single TCAs derived from wild-type littermate controls (mGluR5 ${ }^{\mathrm{f} / \mathrm{f}}, n=12$ TCAs from 6 animals), mGluR5 $^{+/-}$mice $(n=6$ TCAs from 3 animals), and NEX-mGluR5 ${ }^{+/ f}$ mice ( $n=7$ TCAs from 3 animals), and their data were pooled together as the control group. In control TCAs, highly branched TCA arbors were primarily found in cortical layer IV, where they were often localized within one barrel width (Fig. 8A). In both global- and NEXmGluR5 KO mice, many TCAs had very simple arborization patterns, while their arbors covered a larger area (Fig. $8 B, C$ ) (mGluR5 $^{-\prime-}, n=25$ TCAs from 10 animals; NEX-mGluR5 KO, $n=32$ TCAs from 10 animals).

To quantify the above qualitative observations, various morphometric features of axonal arbor topology were analyzed. In control TCAs, the number of segments per branch order reached a peak around the seventh order. In global- and NEX-mGluR5 KO mice, the number of segments for the fourth to eighth orders was significantly reduced compared to that in controls (Fig. 8D). For many orders, the segment length was greater in mGluR5 ${ }^{-1-}$ and NEX-mGluR5 KO TCAs than control TCAs (Fig. 8 E). In mGluR5 ${ }^{-1-}$ and NEX-mGluR5 KO mice, the total branch number (from the first bifurcation point) of the TCAs was significantly reduced compared to control mice (Fig. $8 F)(p<0.001)$. The total axonal length of $\mathrm{mGluR}^{-1-}$ and NEX-mGluR5 KO TCAs was also significantly reduced com-
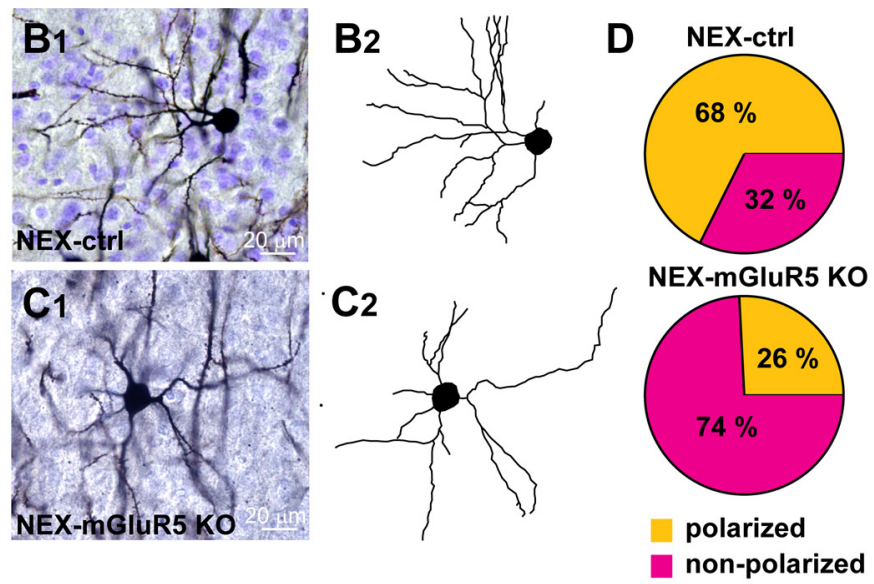
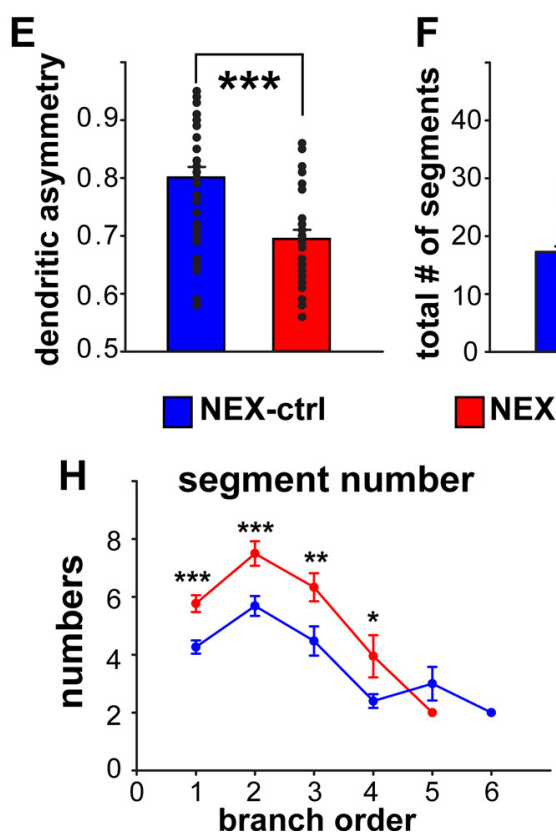

G

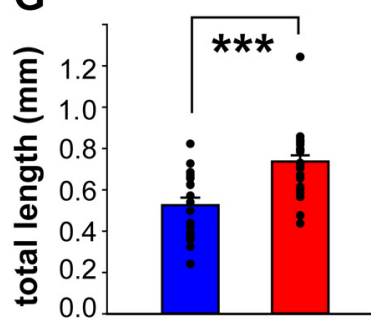

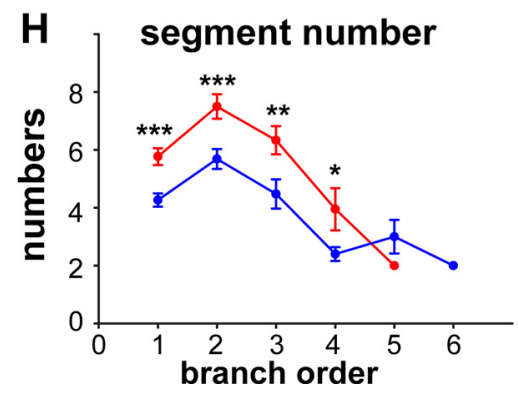

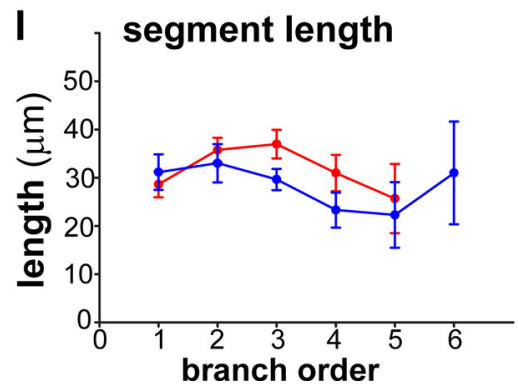

Figure 7. The absence of mGluR5 function in layer IV spiny stellate neurons leads to abnormal dendritic patterning. $\boldsymbol{A}, \mathrm{A}$ low-magnification image shows Golgi-stained S1 cortex of a coronal slice prepared from a P35 NEX-control mouse. The highmagnification view of the barrel field (red dashed box) is shown in B1. B, C, Example images of Golgi-positive spiny stellate neurons from P35 NEX-control (B1) and P35 NEX-mGluR5 KO (C1) S1 cortex. B2, C2, Their computer-aided reconstructions. D, Pie charts showing the percentage of cells with polarized or nonpolarized distributions of dendrites (neurons with a dendritic asymmetry value $>0.75$ were considered to be polarized). $\boldsymbol{E}$, The degree of dendritic asymmetry is significantly lower in NEX-mGluR5 K0 neurons (NEX-control, $0.80 \pm 0.02, n=34$; NEX-mGluR5 K0, $0.70 \pm 0.02, n=31 ; p<0.001$ between NEX-control and NEX-mGluR5 K0). Points indicate the data from individual tracings. $F$, The total number of dendritic segments is significantly higher in NEX-mGluR5 KO neurons (NEX-control, $17.26 \pm 4.25, n=19 ;$ NEX-mGluR5 K0, $22.62 \pm 6.91, n=26 ; p=0.002$ between NEX-control and NEX-mGluR5 KO, Mann-Whitney rank-sum test). G, The total length of dendritic segments is also significantly greater in NEX-mGluR5 K0 neurons (NEX-control, $525.63 \pm 36.74 \mu \mathrm{m}, n=19$; NEX-mGluR5 K0, $736.79 \pm 30.29 \mu \mathrm{m}, n=26$; $p<0.001$ between NEX-control and NEX-mGluR5 K0). $\boldsymbol{H}$, Summary of mean segment number per branch order. $\boldsymbol{I}$, Summary of mean segment length per branch order. Asterisks are used to indicate significant differences from the control group $\left({ }^{*} p<0.05\right.$, ${ }^{* *} p<0.01,{ }^{* * *} p<0.001, t$ test).

pared to those from control mice (Fig. $8 G)(p<0.001)$. However, the lateral extent of the axonal coverage of $m G l u R 5^{-1-}$ and NEX-mGluR5 KO TCAs was significantly wider than control TCAs (Fig. $8 H)\left(p=0.034\right.$ between control and mGluR5 ${ }^{-1-}$; $p=0.022$ between control and NEX-mGluR5 KO). The highest branch order in mGluR5 ${ }^{-1-}$ and NEX-mGluR5 KO mice was also significantly less than in control mice (Fig. $8 I)(p<0.001$ for both comparisons).

In summary, we found similar TCA deficits in the global and NEX-mGluR5 KO mice, including a reduction in the total branch numbers and axonal length, while the lateral axonal span was in- 
A

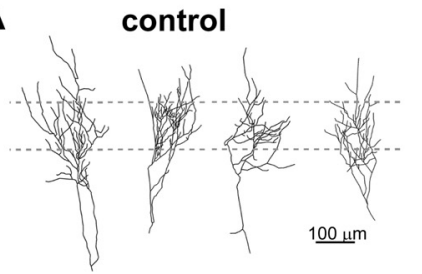

B

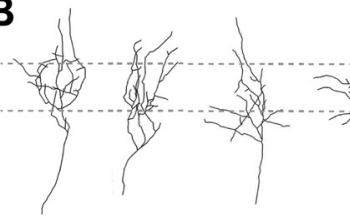

C

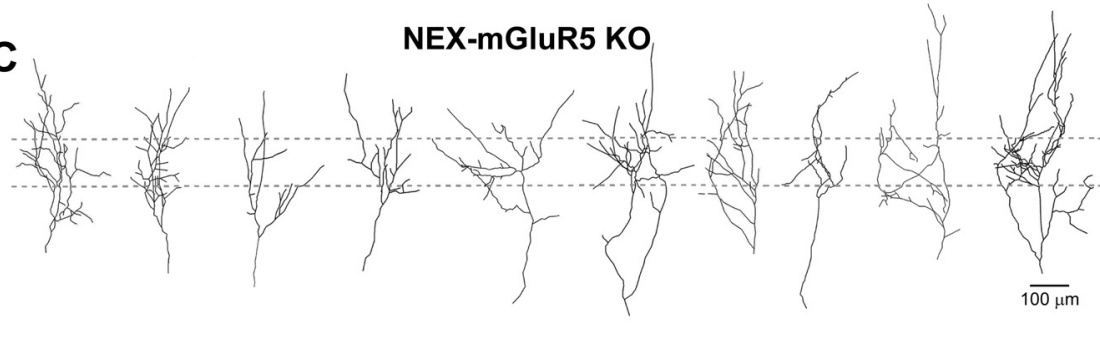

D

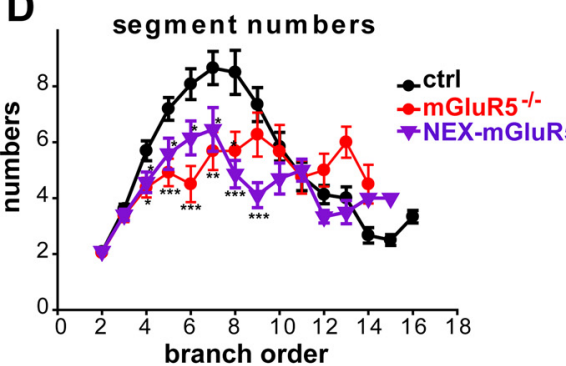

E

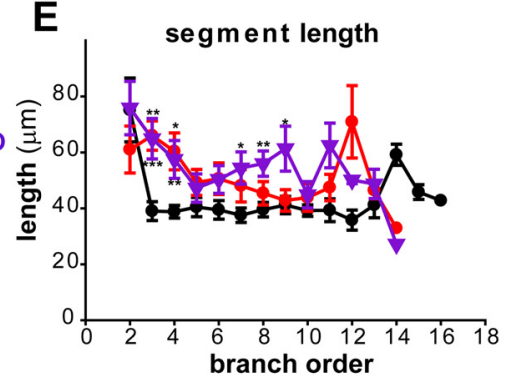

F

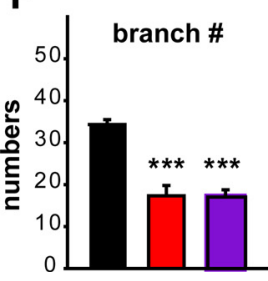

G

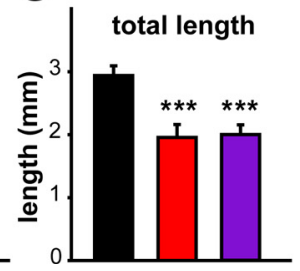

\section{H}

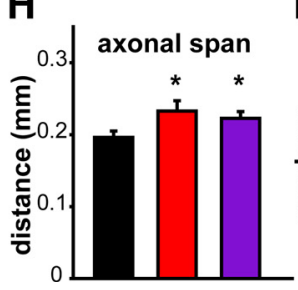

NEX-mGluR5 $5^{\text {f/+ }}$

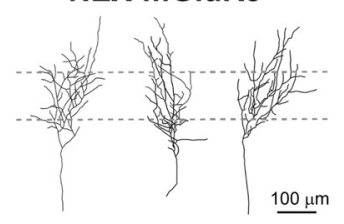

$\underline{100 \mu \mathrm{m}}$

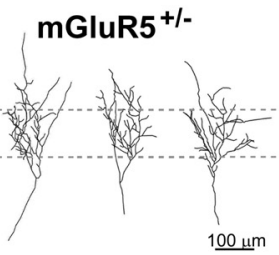

mGluR5 ${ }^{-1-}$

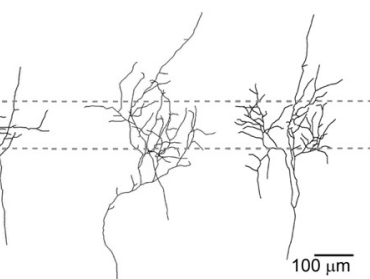

$\mu \mathrm{m}$

\section{?}



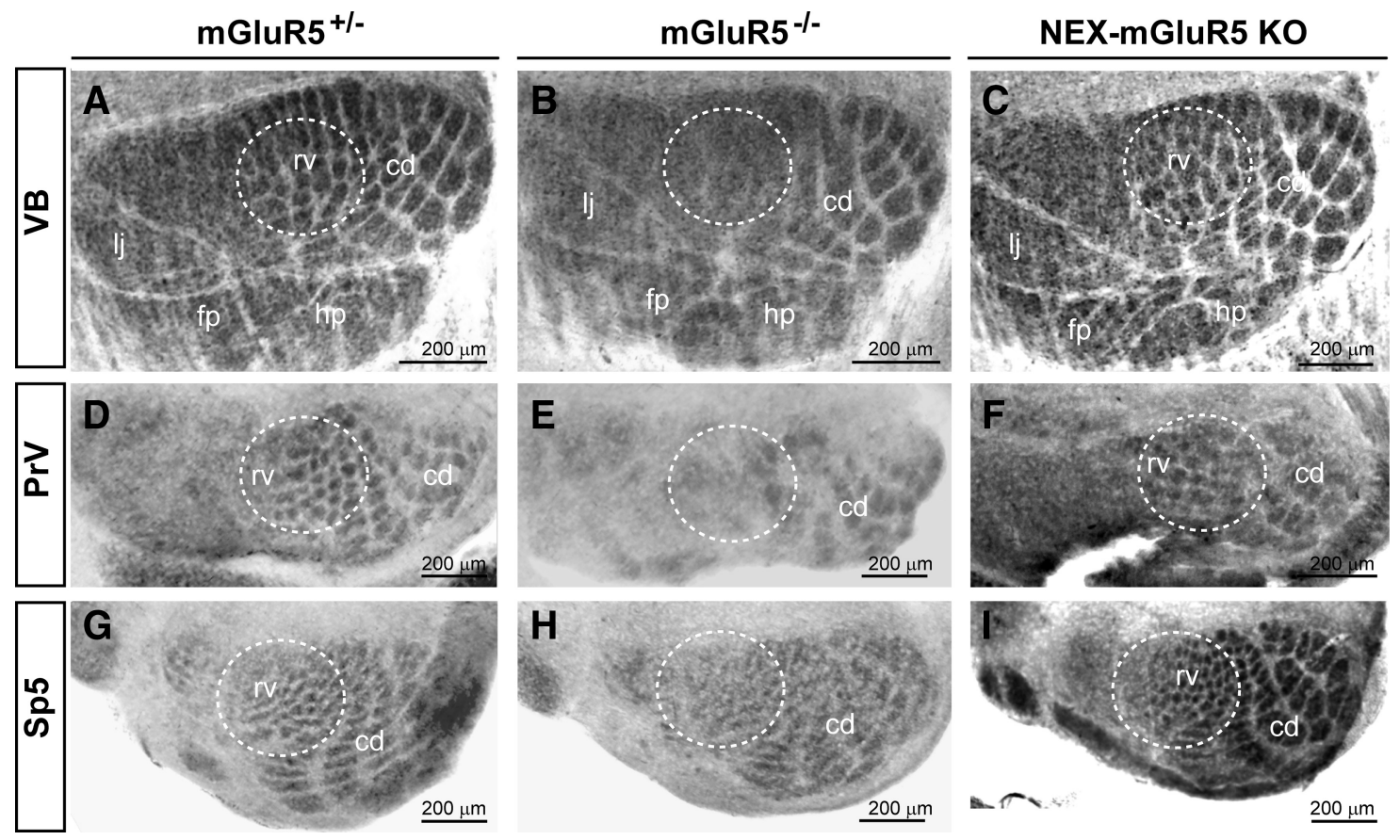

Figure 9. Whisker maps are normal in the subcortical relay stations of NEX-mGluR5 KO mice. CO staining of coronal sections through the ventrobasal thalamus $(\boldsymbol{A}-\boldsymbol{C})$, the principal nucleus (D-F), and the spinal trigeminal nucleus $(\mathbf{G}-\boldsymbol{I})$ of the brainstem trigeminal complex reveals barreloid $(\boldsymbol{A}-\boldsymbol{C})$ and barrelette patterns $(\boldsymbol{D}-\boldsymbol{I})$. In mGluR5 ${ }^{-/-}$mice, $C 0$ patches corresponding to rostroventral whiskers were indistinct, while $C O$ patches corresponding to caudodorsal whiskers were evident $(\boldsymbol{B}, \boldsymbol{E}, \boldsymbol{H})$. Normal whisker presentations for both rostroventral and caudodorsal whiskers in the subcortical relay stations were observed in mGluR5 ${ }^{+/-}(\boldsymbol{A}, \boldsymbol{D}, \boldsymbol{G})$ and NEX-mGluR5 KO$(\boldsymbol{C}, F, I)$.Dashed circles enclose the area representing the rostroventral whiskers. cd, The representation of the caudodorsal whiskers; $f$, forepaw; $h p$, hindpaw; lj, lower jaw; PrV, principal sensory nucleus; $r v$, the representation of the rostroventral whiskers; Sp5, the spinal trigeminal nucleus; VB, the ventrobasal thalamus.

neurons (Fig. 10). mEPSC frequencies were significantly higher in mGluR5 ${ }^{-1-}$ than in mGluR5 ${ }^{+/-}$layer IV neurons (Fig. 10C) ( $p=0.002)$, while no obvious difference was apparent for the mean mEPSC amplitudes (mGluR5 ${ }^{+/-}, 12.08 \pm 0.74 \mathrm{pA}, n=11$; mGluR5 $^{-1-}, 12.88 \pm 0.80 \mathrm{pA}, n=9 ; p=0.471, t$ test). Interestingly, mIPSC frequency was significantly reduced in $\mathrm{mGluR} 5^{-1-}$ mice (Fig. 10D) $(p=0.023)$, while there was no difference in mIPSC amplitude between the genotypes $\left(\mathrm{mGluR}^{+/-}, 23.67 \pm\right.$ $3.56 \mathrm{pA}, n=14$; GGluR5 $^{-1-}, 18.32 \pm 2.81 \mathrm{pA}, n=9 ; p=0.395$, Mann-Whitney $U$ test). The alterations in frequencies but not amplitudes of mEPSCs and mIPSCs in mGluR5 ${ }^{-1-}$ mice suggest that the numbers of functional connections layer IV neurons receive are altered, while the synaptic strengths remain normal. The increase in mEPSC frequency coupled with a reduction in mIPSC frequency in mGluR $5^{-1-}$ mice may lead to an excitatory/ inhibitory imbalance onto cortical layer IV neurons with a shift toward excitation.

Next, we recorded mEPSCs and mIPSCs from layer IV neurons of NEX-mGluR5 $\mathrm{KO}$ mice and their wild-type littermate controls $\left(\mathrm{mGluR} 5^{\mathrm{f} / \mathrm{f}}\right)$. No significant difference in mEPSC frequencies was found in the NEX-mGluR5 KO (NEX-Cre; mGluR $5^{\mathrm{f} / \mathrm{f}}$ ) layer IV neurons (Fig. $10 \mathrm{E}$ ). Interestingly, similar to global mGluR5 KO mice, there was a significant decrease in mIPSC frequency in the NEX-mGluR5 KO mice (Fig. 10F) $(p=$ 0.042). In NEX-mGluR5 KO mice, the amplitudes of both mEPSCs and mIPSCs (data not shown) were similar to littermate controls.

Whole-cell current-clamp recordings were conducted to examine the intrinsic membrane properties of NEX-control $(n=$ 39 neurons from 7 animals) and NEX-mGluR5 KO ( $n=26$ neurons from 6 animals) neurons by injecting somatic current pulses (Fig. 11). In the majority of recorded neurons, depolarizing current pulses evoked a low-frequency train of APs, a typical re- sponse for layer IV regular-spiking (RS) neurons [for examples, see Petersen and Sakmann (2000), Schubert et al. (2003), and Staiger et al. (2004)]. Normal intrinsic membrane properties were found in NEX-mGluR5 KO RS neurons (Table 1). The input-output relationships of AP number triggered by increasing amounts of current were similar between control and NEXmGluR5 KO RS neurons. During AP trains of five to six APs, a gradual decrease in AP amplitude coupled with an elongation of the interspike interval was observed in both control and NEXmGluR5 KO RS neurons. These results show that the absence of mGluR5 function does not affect the examined membrane properties in RS neurons. The decrease in mIPSC frequency in NEXmGluR5 KO mice suggests that mGluR5 in cortical principal neurons modulates the functional development of their GABAergic connections but not glutamatergic connections. Thus, our data argue that the absence of mGluR5 in glutamatergic neurons leads to a reduction in cortical interneuron outputs. mGluR5 signaling in cortical excitatory neurons exerts nonautonomous influences on two distinct presynaptic partners: TCAs and inhibitory interneurons.

\section{Discussion}

Previous studies with global mGluR5 KO mice implicated mGluR5 signaling in cortical map formation. However, the defective whisker maps throughout the whisker-barrel pathway in mGluR5 KO mice make it difficult to determine the origin of mGluR5 signaling in sensory circuit formation. Here we generated cortex-specific mGluR5 KO mice and found that specifically deleting mGluR5 from cortical excitatory neurons using NEXCre results in cortical whisker map deficits similar to that observed in global mGluR5 KO mice. Removing mGluR5 from cortical excitatory neurons disrupted the cytoarchitecture of barrels, dendritic morphogenesis of spiny stellate neurons, and the 


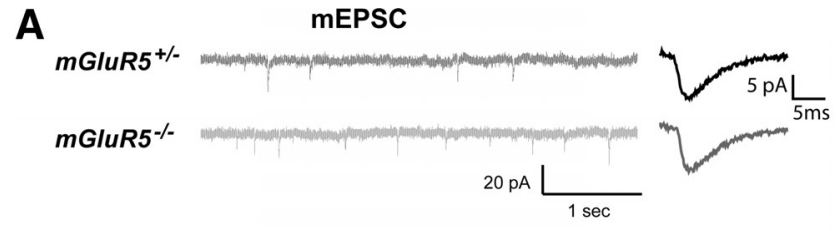

B
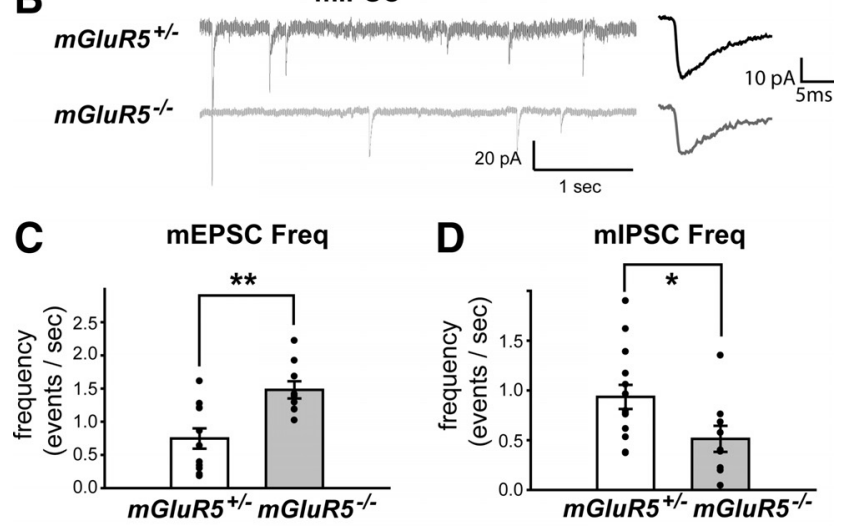

E
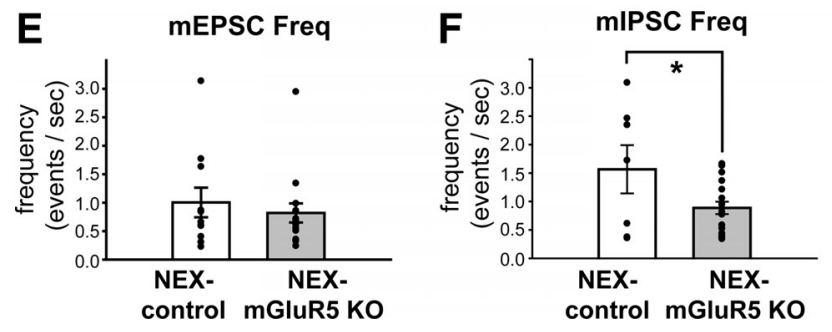

Figure 10. mGluR5 deletion alters functional inputs onto layer IV neurons. $\boldsymbol{A}, \boldsymbol{B}$, Example recordings of mEPSCs $(\boldsymbol{A})$ and mIPSCS $(\boldsymbol{B})$ from layer IV neurons of mGluR5 ${ }^{+/-}$and mGluR5 ${ }^{-1-}$ mice. Representative single mEPSCs and mIPSCs are shown on the right. $C$, Summaries of $\mathrm{mEPSC}$ frequencies from mGluR5 ${ }^{+/-}$and $\mathrm{mGluR5^{-1- }}$ mice (mGluR5 ${ }^{+/-}, 0.75 \pm$ 0.15 events $/ \mathrm{s}, n=11 ; \mathrm{mGluR5}^{-1-}, 1.48 \pm 0.13$ events $/ \mathrm{s}, n=9 ; p=0.002, t$ test). $\boldsymbol{D}$, Summary of mIPSC frequencies from mGluR5 $5^{+/-}$and $\mathrm{mGluR5}^{-1-}$ mice (mGluR5 ${ }^{+-}$, $0.94 \pm 0.12$ events $/ \mathrm{s}, n=14 ; \mathrm{mGluR5}^{-1-}, 0.51 \pm 0.13$ events $/ \mathrm{s}, n=9 ; p=0.023, t$ test). $E$, Summaries of mEPSC frequencies from control and NEX-mGluR5 K0 mice (control, $1.00 \pm$ 0.26 events $/ s, n=11$; NEX-mGluR5 ${ }^{-1-}, 0.82 \pm 0.17$ events $/ s, n=15 ; p=0.88$, MannWhitney $U$ test). $\boldsymbol{F}$, Summaries of mIPSC frequencies from NEX-control and NEX-mGluR5 KO mice (control, $1.57 \pm 0.42$ events $/ s, n=8$; NEX-mGluR5 K0, $0.89 \pm 0.11$ events $/ \mathrm{s}, n=12$; $p=0.042$ by $t$ test). Points indicate the data from individual recordings.

patterning of TCAs. The TCA patterning deficits observed in NEX-mGluR5 KO mice suggest that retrograde signaling induced by mGluR5 plays an important role in guiding the growth of TCAs into a compact and highly branched pattern within their corresponding barrels. At the functional level, removing mGluR5 from cortical glutamatergic neurons reduced GABAergic inputs onto layer IV neurons. Together, these results suggest that mGluR5 signaling in cortical glutamatergic neurons exerts both cell-autonomous and -nonautonomous effects that orchestrate the proper anatomical and functional development of several aspects of cortical somatosensory circuits.

\section{mGluR5 signaling in cortical principal neurons is required for barrel formation}

The complete absence of barrel cytoarchitecture in NEXmGluR5 KO mice in a 129/C57BL6 genetic background indicates a requirement for mGluR5 signaling in cortical layer IV excitatory neurons in orchestrating themselves to form barrel cytoarchitecture [see Hannan et al. (2001) for variations of barrel map deficits of mGluR5 $\mathrm{KO}$ mice in different genetic backgrounds].
"Barrelless" phenotypes have been described in several mutant mice, including (but not limited to) the null mutant mice of the following genes: NMDAR (NR1 and NR2B) (Li et al., 1994; Kutsuwada et al., 1996; Iwasato et al., 1997; Mori et al., 1998; Iwasato et al., 2000), MAOA (monoamine oxidase A) (Cases et al., 1996), 5HTT (serotonin transporter) (Persico et al., 2001; Salichon et al., 2001), adenylyl cyclase I (AC1; barrelless ${ }^{\text {Adcyl }}$ ) (Welker et al., 1996), PKARII $\beta$ (PKA regulatory subunit II $\beta$ ) (Inan et al., 2006; Watson et al., 2006), and Neuro-D2 (Ince-Dunn et al., 2006). The nature of these mutations suggests that glutamatergic and serotonergic neurotransmission, cAMP/PKA signaling, and activitydependent transcription are all involved in forming barrel cytoarchitecture. The majority of layer IV excitatory neurons are spiny stellate neurons that project their dendrites toward the barrel hollow (Woolsey et al., 1975). The reduced dendritic polarity of layer IV spiny stellate neurons in many of these "barrelless" mutant mice (e.g., mGluR5, NR1, and PKARII $\beta$ KO mice) together with our observations with NEX-mGluR5 KO mice suggests a link between asymmetric dendritic morphogenesis and barrel cytoarchitecture formation. Thus, the barrelless phenotype in NEX-mGluR5 KO mice is likely caused by aberrant dendritic morphogenesis of layer IV stellate neurons observed in mGluR5 KO neurons. The observed increases in the number of dendritic segments and total dendritic length in mGluR5 KO stellate neurons are similar to the reported phenotype in cortexNR1 KO mice (Datwani et al., 2002), raising the possibility that mGluR5 and NMDAR collaborate in regulating dendritic outgrowth.

Specific removal of the mGluR5 gene in principal cortical neurons by NEX-Cre reduces cortical mGluR5 expression by $>70 \%$ (see Fig. 4). The difference in mGluR5 expression levels between NEX- and EMX-mGluR5 KO S1 cortex ( 10\%) may reflect glial mGluR5. mGluR5 expression in interneurons has also been reported (Lujan et al., 1996; Cauli et al., 2000; van Hooft et al., 2000; López-Bendito et al., 2002) and thus the residual lowlevel mGluR5 expression $(\sim 17 \%)$ detected in developing EMXmGluR5 KO S1 cortex is likely to reflect interneuronal mGluR5 expression.

\section{Nonautonomous influences of mGluR5 signaling on TCA patterning}

The abnormal TCA patterns observed in cortex-mGluR5 KO mice implicate a nonautonomous influence of mGluR5 signaling on TCA patterning. Comparisons of single TCAs from globaland NEX-mGluR5 KO mice with TCAs from their littermate controls revealed several differences in axonal arborizations. After entering cortical layer IV, control TCAs form highly branched and densely clustered arbors. In global- and NEX-mGluR5 KO mice, TCAs formed significantly fewer branches but spanned a wider area. The total lengths of their axonal arbors were also significantly shorter. Single TCA morphometric analysis revealed that the arborization deficits observed in the global and NEXmGluR5 KO TCAs were almost identical. mGluR5 KO thalamocortical synapses have normal short-term plasticity and release probabilities (She et al., 2009). This suggests that mGluR5 signaling in cortical excitatory neurons orchestrates TCA patterning, especially for the formation of axonal collaterals, but has no obvious impact on TCA release machinery.

NMDAR and mGluR5 interact through adaptor proteins (Fagni et al., 2004) and reciprocally modulate each other's function (Alagarsamy et al., 2002; Heidinger et al., 2002; Guo et al., 2004; Alagarsamy et al., 2005). Similar to cortex-mGluR5 KO mice, cortex-specific removal of NR1 also leads to rudimentary 
A

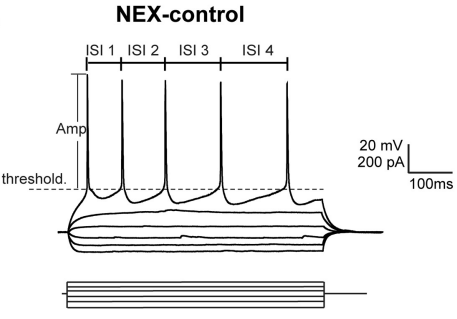

B

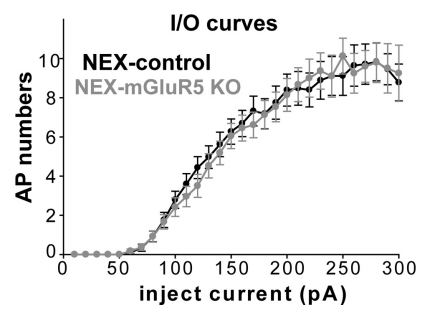

C

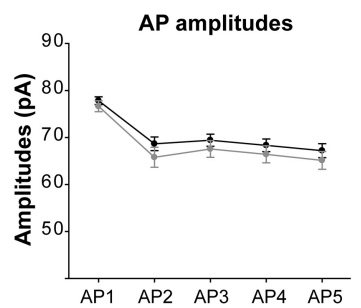

NEX-mGluR5 KO

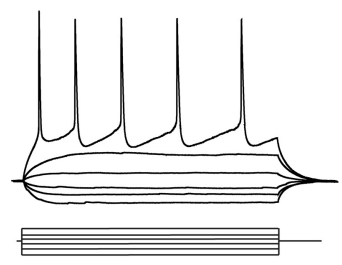

D

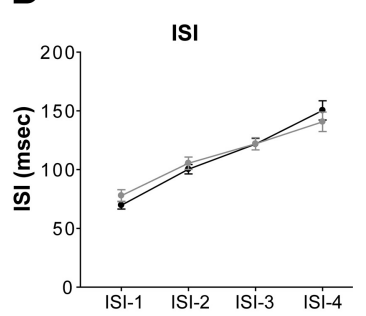

Figure 11. Normal intrinsic membrane properties in mGluR5 KO layer IV regular-spiking neurons. $A$, Example recordings show synaptic responses of regular-spiking neurons recorded from layer IV of NEX-control and NEX-mGluR5 KO S1 cortex triggered by different amount of currents. APs were triggered upon injections of suprathreshold depolarizing current at resting membrane potential. $\boldsymbol{B}$, The summary of the input- output relationships between the number of evoked APs and the amount of injected current. C, Summary of the amplitudes of the first to the fifth AP triggered by current pulses. $D$, Summary for the interspike intervals (ISI) between APs.

Table 1. Summary of intrinsic membrane properties of layer IV regular spiking neurons

\begin{tabular}{lccc}
\hline & Control $(n=39)$ & NEX-mGluR5 K0 $(n=26)$ & $p$ value \\
\hline$V_{\text {rest }}(\mathrm{mV})$ & $-60.32 \pm 0.77$ & $-60.02 \pm 0.85$ & 0.804 \\
$R_{\text {in }}(\mathrm{M} \Omega)$ & $128.3 \pm 5.8$ & $132.1 \pm 11.2$ & 0.746 \\
Spike threshold $(\mathrm{mV})$ & $-36.91 \pm 0.35$ & $-36.20 \pm 0.56$ & 0.259 \\
1st AP amplitude $(\mathrm{mV})$ & $76.43 \pm 0.77$ & $75.39 \pm 1.18$ & 0.443 \\
AHP amplitude $(\mathrm{mV})$ & $-9.11 \pm 0.46$ & $-9.32 \pm 0.75$ & 0.796 \\
$T_{\text {AHP }}$ (ms) & $40.93 \pm 1.43$ & $45.03 \pm 2.11$ & 0.102 \\
Rheobase $(\mathrm{pA})$ & $107.1 \pm 6.0$ & $104.0 \pm 7.2$ & 0.743 \\
$\tau_{\mathrm{m}}$ (ms) & $8.09 \pm 0.37$ & $9.50 \pm 0.75$ & 0.068 \\
\hline
\end{tabular}

All the values listed are mean \pm SEM and analyzed with unpaired Student's $t$ test (two-tailed). Rheobase, The lowest injected current for triggering an AP from resting membrane potential; $T_{\text {AHP }}$, time of afterhyperpolarization.

TCA patterns (Iwasato et al., 2000; Datwani et al., 2002). However, in contrast to the reduced TCA complexity in mGluR5 KO mice, single TCAs in cortex-NR1 KO mice have exuberant branches (Lee et al., 2005). Thus, mGluR5 and NMDAR exert different effects on TCA arborization.

The TCA patterning deficits observed in cortex-mGluR5 KO mice suggest that retrograde signaling induced by metabotropic glutamate receptors plays an important role in guiding the growth of TCAs into a compact and highly branched pattern in their corresponding barrels. Several activity-dependent retrograde messengers made postsynaptically and acting presynaptically have been identified (for review, see Regehr et al., 2009), including endocannabinoids, nitric oxide, neuropeptides, neurotransmitters (e.g., glutamate), trophic factors (e.g., BDNF), ephrin/Eph, etc. Many studies have found that mGluR5 signaling regulates the synthesis of endocannabinoids and BDNF in the postsynaptic compartments to presynaptically modulate neurotransmission. BDNF and several ephrin/Eph are expressed in the developing S1 cortex (Itami et al., 2000; Vanderhaeghen et al., 2000; Bolz et al., 2004), and in vitro studies found that BDNF and ephrin/Eph can promote TCA axonal branching (Gao et al., 1998; Mann et al., 2002; Hanamura et al., 2004). Despite a grossly normal whisker map in S1 cortex, the complexity of TCA arbors is reduced in Ephrin-A5 KO mice (Vander- haeghen et al., 2000; Uziel et al., 2008). Which factor(s) mediate the retrograde influence of mGluR5 signaling in patterning TCAs remains to be determined.

\section{The absence of mGluR5 in excitatory neurons decreases inhibitory inputs} In both NEX- and global-mGluR5 $\mathrm{KO}$ mice, the reduced mIPSC frequency recorded in layer IV neurons suggests that mGluR5 in glutamatergic cortical neurons determines the number of functional GABAergic connections received by layer IV neurons. The role of group I mGluR in regulating the outputs of interneurons has also been shown in the thalamus using a pharmacological approach (Govindaiah and Cox, 2006, 2009). Homeostatic compensation is unlikely to account for the reduced GABAergic input in NEXmGluR5 KO neurons because they have normal glutamatergic strength and intrinsic excitability. In visual cortex, modulating the strength of GABA circuits during development alters TCA spacing (Hensch and Stryker, 2004; Sarihi et al., 2008), and thus, it is possible that excitatory/inhibitory balance in the S1 cortex influences whisker-related TCA clustering.

The increase in mEPSC frequency in global mGluR5 $\mathrm{KO}$ mice but not in NEX-mGluR5 KO mice suggests that mGluR5 in cortical principal neurons does not determine the glutamatergic connections received by layer IV neurons. Abnormal TCA arborization is unlikely to account for the increase in mEPSC frequency found in global mGluR5 KO mice because similar TCA patterning deficits were found in both strains. It is possible that mGluR5 deletion in NEX-mGluR5 KO mice occurs after excitatory connections are established or mGluR5 expression outside cortical pyramidal neurons regulates glutamatergic connections.

The majority of inhibitory neurons connected to layer IV excitatory neurons receive direct inputs from TCAs (Porter et al., 2001; Bruno and Simons, 2002; Inoue and Imoto, 2006; Sun et al., 2006; Cruikshank et al., 2007; Daw et al., 2007; Tan et al., 2008). Thus, spikes in thalamic axons excite both excitatory and inhibitory cortical neurons and trigger a fast feedforward inhibition (Agmon and Connors, 1991; Swadlow and Gusev, 2000; Beierlein et al., 2002). This functional architecture leads to a precise sequence of excitation followed by inhibition in response to sensory inputs. This pattern may serve to limit the temporal window for integration and sharpens the temporal resolution of thalamic inputs (Pinto et al., 2000; Pouille and Scanziani, 2001). It will be interesting to determine whether the reduced GABAergic inputs onto layer IV neurons found in NEX- and global-mGluR5 KO mice will lead to defective sensory processing in vivo.

In sum, here we demonstrate that mGluR5 in cortical glutamatergic neurons is required for the proper development of the cortical barrel map in layer IV. mGluR5 signaling in cortical excitatory neurons not only instructs their own morphogenesis but also modulates the patterning of their presynaptic counterparts: the TCAs and GABAergic interneurons via unknown retrograde messages. The cortical excitatory neuron-specific mGluR5 $\mathrm{KO}$ mice will provide a great tool to elucidate the mechanism(s) underlying the coordinated 
development of sensory circuits with appropriate excitatory-inhibitory balance.

\section{References}

Agmon A, Connors BW (1991) Thalamocortical responses of mouse somatosensory (barrel) cortex in vitro. Neuroscience 41:365-379.

Alagarsamy S, Rouse ST, Junge C, Hubert GW, Gutman D, Smith Y, Conn PJ (2002) NMDA-induced phosphorylation and regulation of mGluR5. Pharmacol Biochem Behav 73:299-306.

Alagarsamy S, Saugstad J, Warren L, Mansuy IM, Gereau RW 4th, Conn PJ (2005) NMDA-induced potentiation of mGluR5 is mediated by activation of protein phosphatase $2 \mathrm{~B} /$ calcineurin. Neuropharmacology 49 [Suppl 1]:135-145.

Beierlein M, Fall CP, Rinzel J, Yuste R (2002) Thalamocortical bursts trigger recurrent activity in neocortical networks: layer 4 as a frequencydependent gate. J Neurosci 22:9885-9894.

Blue ME, Martin LJ, Brennan EM, Johnston MV (1997) Ontogeny of nonNMDA glutamate receptors in rat barrel field cortex: I. Metabotropic receptors. J Comp Neurol 386:16-28.

Bolz J, Uziel D, Mühlfriedel S, Güllmar A, Peuckert C, Zarbalis K, Wurst W, Torii M, Levitt P (2004) Multiple roles of ephrins during the formation of thalamocortical projections: maps and more. J Neurobiol 59:82-94.

Bruno RM, Simons DJ (2002) Feedforward mechanisms of excitatory and inhibitory cortical receptive fields. J Neurosci 22:10966-10975.

Cases O, Vitalis T, Seif I, De Maeyer E, Sotelo C, Gaspar P (1996) Lack of barrels in the somatosensory cortex of monoamine oxidase A-deficient mice: role of a serotonin excess during the critical period. Neuron 16:297-307.

Catania MV, D’Antoni S, Bonaccorso CM, Aronica E, Bear MF, Nicoletti F (2007) Group I metabotropic glutamate receptors: a role in neurodevelopmental disorders? Mol Neurobiol 35:298-307.

Cauli B, Porter JT, Tsuzuki K, Lambolez B, Rossier J, Quenet B, Audinat E (2000) Classification of fusiform neocortical interneurons based on unsupervised clustering. Proc Natl Acad Sci U S A 97:6144-6149.

Crair MC, Malenka RC (1995) A critical period for long-term potentiation at thalamocortical synapses. Nature 375:325-328.

Cruikshank SJ, Lewis TJ, Connors BW (2007) Synaptic basis for intense thalamocortical activation of feedforward inhibitory cells in neocortex. Nat Neurosci 10:462-468.

Datwani A, Iwasato T, Itohara S, Erzurumlu RS (2002) NMDA receptordependent pattern transfer from afferents to postsynaptic cells and dendritic differentiation in the barrel cortex. Mol Cell Neurosci 21:477-492.

Daw MI, Ashby MC, Isaac JT (2007) Coordinated developmental recruitment of latent fast spiking interneurons in layer IV barrel cortex. Nat Neurosci 10:453-461.

Erzurumlu RS, Kind PC (2001) Neural activity: sculptor of 'barrels' in the neocortex. Trends Neurosci 24:589-595.

Espinosa JS, Wheeler DG, Tsien RW, Luo L (2009) Uncoupling dendrite growth and patterning: single-cell knockout analysis of NMDA receptor 2B. Neuron 62:205-217.

Fagni L, Ango F, Perroy J, Bockaert J (2004) Identification and functional roles of metabotropic glutamate receptor-interacting proteins. Semin Cell Dev Biol 15:289-298.

Fox K (2008) Barrel cortex, Ed 1. Cambridge: Cambridge UP.

Fujiyama F, Furuta T, Kaneko T (2001) Immunocytochemical localization of candidates for vesicular glutamate transporters in the rat cerebral cortex. J Comp Neurol 435:379-387.

Gao PP, Yue Y, Zhang JH, Cerretti DP, Levitt P, Zhou R (1998) Regulation of thalamic neurite outgrowth by the Eph ligand ephrin-A5: implications in the development of thalamocortical projections. Proc Natl Acad Sci U S A 95:5329-5334.

Goebbels S, Bormuth I, Bode U, Hermanson O, Schwab MH, Nave KA (2006) Genetic targeting of principal neurons in neocortex and hippocampus of NEX-Cre mice. Genesis 44:611-621.

Gorski JA, Talley T, Qiu M, Puelles L, Rubenstein JL, Jones KR (2002) Cortical excitatory neurons and glia, but not GABAergic neurons, are produced in the Emx1-expressing lineage. J Neurosci 22:6309-6314.

Govindaiah G, Cox CL (2006) Metabotropic glutamate receptors differentially regulate GABAergic inhibition in thalamus. J Neurosci 26:1344313453.

Govindaiah G, Cox CL (2009) Distinct roles of metabotropic glutamate re- ceptor activation on inhibitory signaling in the ventral lateral geniculate nucleus. J Neurophysiol 101:1761-1773.

Guo W, Wei F, Zou S, Robbins MT, Sugiyo S, Ikeda T, Tu JC, Worley PF, Dubner R, Ren K (2004) Group I metabotropic glutamate receptor NMDA receptor coupling and signaling cascade mediate spinal dorsal horn NMDA receptor $2 \mathrm{~B}$ tyrosine phosphorylation associated with inflammatory hyperalgesia. J Neurosci 24:9161-9173.

Hanamura K, Harada A, Katoh-Semba R, Murakami F, Yamamoto N (2004) BDNF and NT-3 promote thalamocortical axon growth with distinct substrate and temporal dependency. Eur J Neurosci 19:1485-1493.

Hannan AJ, Blakemore C, Katsnelson A, Vitalis T, Huber KM, Bear M, Roder J, Kim D, Shin HS, Kind PC (2001) PLC-betal, activated via mGluRs, mediates activity-dependent differentiation in cerebral cortex. Nat Neurosci 4:282-288.

Heidinger V, Manzerra P, Wang XQ, Strasser U, Yu SP, Choi DW, Behrens MM (2002) Metabotropic glutamate receptor 1-induced upregulation of NMDA receptor current: mediation through the Pyk2/Src-family kinase pathway in cortical neurons. J Neurosci 22:5452-5461.

Hensch TK, Stryker MP (2004) Columnar architecture sculpted by GABA circuits in developing cat visual cortex. Science 303:1678-1681.

Hur EE, Zaborszky L (2005) Vglut2 afferents to the medial prefrontal and primary somatosensory cortices: a combined retrograde tracing in situ hybridization. J Comp Neurol 483:351-373.

Inan M, Crair MC (2007) Development of cortical maps: perspectives from the barrel cortex. Neuroscientist 13:49-61.

Inan M, Lu HC, Albright MJ, She WC, Crair MC (2006) Barrel map development relies on protein kinase A regulatory subunit II beta-mediated cAMP signaling. J Neurosci 26:4338-4349.

Ince-Dunn G, Hall BJ, Hu SC, Ripley B, Huganir RL, Olson JM, Tapscott SJ, Ghosh A (2006) Regulation of thalamocortical patterning and synaptic maturation by NeuroD2. Neuron 49:683-695.

Inoue T, Imoto K (2006) Feedforward inhibitory connections from multiple thalamic cells to multiple regular-spiking cells in layer 4 of the somatosensory cortex. J Neurophysiol 96:1746-1754.

Itami C, Mizuno K, Kohno T, Nakamura S (2000) Brain-derived neurotrophic factor requirement for activity-dependent maturation of glutamatergic synapse in developing mouse somatosensory cortex. Brain Res 857:141-150

Iwasato T, Erzurumlu RS, Huerta PT, Chen DF, Sasaoka T, Ulupinar E, Tonegawa S (1997) NMDA receptor-dependent refinement of somatotopic maps. Neuron 19:1201-1210.

Iwasato T, Datwani A, Wolf AM, Nishiyama H, Taguchi Y, Tonegawa S, Knöpfel T, Erzurumlu RS, Itohara S (2000) Cortex-restricted disruption of NMDAR1 impairs neuronal patterns in the barrel cortex. Nature 406:726-731.

Jacobowitz D, Abbott L (1998) Chemoarchitectonic atlas of the developing mouse brain. Boca Raton, FL: CRC.

Kettunen P, Kyriakatos A, Hallén K, El Manira A (2005) Neuromodulation via conditional release of endocannabinoids in the spinal locomotor network. Neuron 45:95-104.

Killackey HP, Leshin S (1975) The organization of specific thalamocortical projections to the posteromedial barrel subfield of the rat somatic sensory cortex. Brain Res 86:469-472.

Kind PC, Neumann PE (2001) Plasticity: downstream of glutamate. Trends Neurosci 24:553-555.

Kreitzer AC, Malenka RC (2005) Dopamine modulation of state-dependent endocannabinoid release and long-term depression in the striatum. J Neurosci 25:10537-10545.

Kutsuwada T, Sakimura K, Manabe T, Takayama C, Katakura N, Kushiya E, Natsume R, Watanabe M, Inoue Y, Yagi T, Aizawa S, Arakawa M, Takahashi T, Nakamura Y, Mori H, Mishina M (1996) Impairment of suckling response, trigeminal neuronal pattern formation, and hippocampal LTD in NMDA receptor epsilon 2 subunit mutant mice. Neuron 16:333-344.

Lee LJ, Iwasato T, Itohara S, Erzurumlu RS (2005) Exuberant thalamocortical axon arborization in cortex-specific NMDAR1 knockout mice. J Comp Neurol 485:280-292.

Li Y, Erzurumlu RS, Chen C, Jhaveri S, Tonegawa S (1994) Whisker-related neuronal patterns fail to develop in the trigeminal brainstem nuclei of NMDAR1 knockout mice. Cell 76:427-437.

López-Bendito G, Shigemoto R, Fairén A, Luján R (2002) Differential dis- 
tribution of group I metabotropic glutamate receptors during rat cortical development. Cereb Cortex 12:625-638.

Lu HC, Gonzalez E, Crair MC (2001) Barrel cortex critical period plasticity is independent of changes in NMDA receptor subunit composition. Neuron 32:619-634.

Lübke J, Egger V, Sakmann B, Feldmeyer D (2000) Columnar organization of dendrites and axons of single and synaptically coupled excitatory spiny neurons in layer 4 of the rat barrel cortex. J Neurosci 20:5300-5311.

Lujan R, Nusser Z, Roberts JD, Shigemoto R, Somogyi P (1996) Perisynaptic location of metabotropic glutamate receptors mGluR1 and mGluR5 on dendrites and dendritic spines in the rat hippocampus. Eur J Neurosci $8: 1488-1500$.

Lüscher C, Huber KM (2010) Group 1 mGluR-dependent synaptic longterm depression: mechanisms and implications for circuitry and disease. Neuron 65:445-459.

Mann F, Peuckert C, Dehner F, Zhou R, Bolz J (2002) Ephrins regulate the formation of terminal axonal arbors during the development of thalamocortical projections. Development 129:3945-3955.

Mori H, Manabe T, Watanabe M, Satoh Y, Suzuki N, Toki S, Nakamura K, Yagi T, Kushiya E, Takahashi T, Inoue Y, Sakimura K, Mishina M (1998) Role of the carboxy-terminal region of the GluR epsilon2 subunit in synaptic localization of the NMDA receptor channel. Neuron 21:571-580.

Muñoz A, Liu XB, Jones EG (1999) Development of metabotropic glutamate receptors from trigeminal nuclei to barrel cortex in postnatal mouse. J Comp Neurol 409:549-566.

Nahmani M, Erisir A (2005) VGluT2 immunochemistry identifies thalamocortical terminals in layer 4 of adult and developing visual cortex. J Comp Neurol 484:458-473.

Niswender CM, Conn PJ (2010) Metabotropic glutamate receptors: physiology, pharmacology, and disease. Annu Rev Pharmacol Toxicol 50:295322.

Persico AM, Mengual E, Moessner R, Hall FS, Revay RS, Sora I, Arellano J, DeFelipe J, Gimenez-Amaya JM, Conciatori M, Marino R, Baldi A, Cabib S, Pascucci T, Uhl GR, Murphy DL, Lesch KP, Keller F (2001) Barrel pattern formation requires serotonin uptake by thalamocortical afferents, and not vesicular monoamine release. J Neurosci 21:6862-6873.

Petersen CC (2007) The functional organization of the barrel cortex. Neuron 56:339-355.

Petersen CC, Sakmann B (2000) The excitatory neuronal network of rat layer 4 barrel cortex. J Neurosci 20:7579-7586.

Pinto DJ, Brumberg JC, Simons DJ (2000) Circuit dynamics and coding strategies in rodent somatosensory cortex. J Neurophysiol 83:1158-1166.

Porter JT, Johnson CK, Agmon A (2001) Diverse types of interneurons generate thalamus-evoked feedforward inhibition in the mouse barrel cortex. J Neurosci 21:2699-2710.

Pouille F, Scanziani M (2001) Enforcement of temporal fidelity in pyramidal cells by somatic feed-forward inhibition. Science 293:1159-1163.

Ramón-Moliner E (1970) The Golgi-Cox technique. In: Contemporary research methods in neuroanatomy (Nauta WJH, Ebbesson SOE, eds), pp 32-55. New York: Springer.

Rebsam A, Seif I, Gaspar P (2002) Refinement of thalamocortical arbors and emergence of barrel domains in the primary somatosensory cortex: a study of normal and monoamine oxidase A knock-out mice. J Neurosci 22:8541-8552.

Regehr WG, Carey MR, Best AR (2009) Activity-dependent regulation of synapses by retrograde messengers. Neuron 63:154-170.

Rouach N, Nicoll RA (2003) Endocannabinoids contribute to short-term but not long-term mGluR-induced depression in the hippocampus. Eur J Neurosci 18:1017-1020.

Safo PK, Regehr WG (2005) Endocannabinoids control the induction of cerebellar LTD. Neuron 48:647-659.

Salichon N, Gaspar P, Upton AL, Picaud S, Hanoun N, Hamon M, De Maeyer
E, Murphy DL, Mossner R, Lesch KP, Hen R, Seif I (2001) Excessive activation of serotonin (5-HT) $1 \mathrm{~B}$ receptors disrupts the formation of sensory maps in monoamine oxidase A and 5-HT transporter knock-out mice. J Neurosci 21:884-896.

Sarihi A, Jiang B, Komaki A, Sohya K, Yanagawa Y, Tsumoto T (2008) Metabotropic glutamate receptor type 5-dependent long-term potentiation of excitatory synapses on fast-spiking GABAergic neurons in mouse visual cortex. J Neurosci 28:1224-1235.

Schubert D, Kötter R, Zilles K, Luhmann HJ, Staiger JF (2003) Cell typespecific circuits of cortical layer IV spiny neurons. J Neurosci 23:29612970.

She WC, Quairiaux C, Albright MJ, Wang YC, Sanchez DE, Chang PS, Welker E, Lu HC (2009) Roles of mGluR5 in synaptic function and plasticity of the mouse thalamocortical pathway. Eur J Neurosci 29:1379-1396.

Staiger JF, Flagmeyer I, Schubert D, Zilles K, Kötter R, Luhmann HJ (2004) Functional diversity of layer IV spiny neurons in rat somatosensory cortex: quantitative morphology of electrophysiologically characterized and biocytin labeled cells. Cereb Cortex 14:690-701.

Steffen H, Van der Loos H (1980) Early lesions of mouse vibrissal follicles: their influence on dendrite orientation in the cortical barrelfield. Exp Brain Res 40:419-431.

Sun QQ, Huguenard JR, Prince DA (2006) Barrel cortex microcircuits: thalamocortical feedforward inhibition in spiny stellate cells is mediated by a small number of fast-spiking interneurons. J Neurosci 26:1219-1230.

Swadlow HA, Gusev AG (2000) The influence of single VB thalamocortical impulses on barrel columns of rabbit somatosensory cortex. J Neurophysiol 83:2802-2813.

Takasaki C, Okada R, Mitani A, Fukaya M, Yamasaki M, Fujihara Y, Shirakawa T, Tanaka K, Watanabe M (2008) Glutamate transporters regulate lesion-induced plasticity in the developing somatosensory cortex. J Neurosci 28:4995-5006.

Tan Z, Hu H, Huang ZJ, Agmon A (2008) Robust but delayed thalamocortical activation of dendritic-targeting inhibitory interneurons. Proc Natl Acad Sci U S A 105:2187-2192.

Uziel D, Mühlfriedel S, Bolz J (2008) Ephrin-A5 promotes the formation of terminal thalamocortical arbors. Neuroreport 19:877-881.

Vanderhaeghen P, Lu Q, Prakash N, Frisén J, Walsh CA, Frostig RD, Flanagan JG (2000) A mapping label required for normal scale of body representation in the cortex. Nat Neurosci 3:358-365.

van Hooft JA, Giuffrida R, Blatow M, Monyer H (2000) Differential expression of group I metabotropic glutamate receptors in functionally distinct hippocampal interneurons. J Neurosci 20:3544-3551.

Watson RF, Abdel-Majid RM, Barnett MW, Willis BS, Katsnelson A, Gillingwater TH, McKnight GS, Kind PC, Neumann PE (2006) Involvement of protein kinase A in patterning of the mouse somatosensory cortex. J Neurosci 26:5393-5401.

Welker E, Armstrong-James M, Bronchti G, Ourednik W, GheorghitaBaechler F, Dubois R, Guernsey DL, Van der Loos H, Neumann PE (1996) Altered sensory processing in the somatosensory cortex of the mouse mutant barrelless. Science 271:1864-1867.

Wijetunge LS, Till SM, Gillingwater TH, Ingham CA, Kind PC (2008) mGluR5 regulates glutamate-dependent development of the mouse somatosensory cortex. J Neurosci 28:13028-13037.

Woolsey TA, Van der Loos H (1970) The structural organization of layer IV in the somatosensory region (SI) of the mouse cerebral cortex. Brain Res 17:205-242.

Woolsey TA, Dierker ML, Wann DF (1975) Mouse SmI cortex: qualitative and quantitative classification of golgi-impregnated barrel neurons. Proc Natl Acad Sci U S A 72:2165-2169.

Xu J, Zhu Y, Contractor A, Heinemann SF (2009) mGluR5 has a critical role in inhibitory learning. J Neurosci 29:3676-3684. 